\title{
Colour and the Critique of Advertising: Privilege (Peter Watkins, 1967) and Herostratus (Don Levy, 1967)
}

Sarah Street

https://doi.org/10.15664/fcj.v0i17.2072

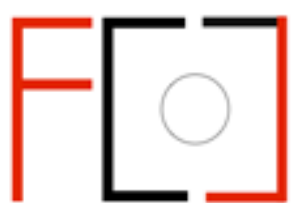

Frames Cinema Journal

ISSN 2053-8812

Issue 17 (Jun 2020)

(c) (i)

http://www.framescinemajournal.com 


\section{Colour and the Critique of Advertising: Privilege (Peter Watkins, 1967) and Herostratus (Don Levy, 1967) \\ Sarah Street}

In the 1960s colour was at the heart of advertising campaigns designed to appeal to younger consumers. Writing in 1968, marketing theorist and colour consultant Eric P. Danger described a culture that was infused with the increasing vibrancy of colour in homes, industrial environments and television advertisements. ${ }^{1}$ Colour was associated with youth, prosperity and the exercise of consumer choice. Annual advertising expenditure increased in Britain from $£^{277}$ million in 1955 to nearly $£, 500$ million by 1960 , signalling an upward trend, much of it 'aimed at youth, endowing youth with a corporate identity and going a long way to wiping out the more obvious social distinctions'. ${ }^{2}$ Television advertising became a primary outlet for creative brand-building, a trend that was accelerated with the launch of colour television in Britain at the end of the 1960s. ${ }^{3}$

The world of advertising was not, however, uniformly celebrated; some critics condemned its aims and conventions as an artist's sell-out to 'base, conniving, exploiting and selfish' imperatives. ${ }^{4}$ As noted by Schwarzkopf, 'an intense hostility towards advertising' was spearheaded by the Labour Party, and consumer organisations were suspicious of shoppers being duped by misleading and exploitative marketing strategies. ${ }^{5}$ When advertising companies began to deploy 'subliminal' methods through psychological suggestion in the late 1950s, critics became concerned about the sinister and ethical impacts of 'the hidden persuaders' on people's consciousness. ${ }^{6}$ This article explores how film, a primary media form for contemporary advertising cultures, could also be used to critique and satirise that very phenomenon. It focuses on Privilege (Peter Watkins) and Herostratus (Don Levy), two British feature films released in 1967 which delivered uncompromising, bleak visions of an advertising-saturated society that exploited rather than empowered young people. Although they were not widely exhibited on first release, subsequent digital restorations permit their striking colour designs to be more fully appreciated as an integral element of their reassessment as key texts in late 1960s experimental British filmmaking. Although their radical political stances attracted both admiration and criticism, their technical and creative significance has not received sustained analysis, nor has their use of colour. ${ }^{7}$

Herostratus and Privilege deploy colour to expose and exploit its conventions: how saturation, light and texture indicate superficiality not depth in advertising contexts; paradoxically, in a chromatic culture of ephemerality, more is less. The films show how images created for advertising can nevertheless be very powerful in terms of their unambiguous, persuasive messaging. On the other hand, the various new contexts, structural framings and distancing techniques presented in both films suggest deep levels of criticism, revealing power structures at stake, and the potential of colour's active role in their interrogation. They demonstrate how colours in films can become politicised through techniques such as dynamic editing, re-presenting shots and scenes in different contexts. In this analysis a number of theoretical perspectives will be referenced, including Jameson on colour and gloss, Eisenstein on colour and context, and Batchelor on pure colour suffusion. ${ }^{8}$ Eisenstein's theoretical writings, for example, defined a three-phase process for the expressive use of colour comprising the separation between colour and object; the 're-working' of colour, which entails the application of emotional and dramatic functions, and the 'rematerialisation' of colour in objects initiated by these functions. In addition, the films use parody 
and satire, devices that Eisenstein used for political effect in his drawings, theatre work and black and white films but did not have the opportunity to fully develop in respect of colour.

Both Watkins and Levy were non-mainstream British filmmakers, neither of whom had previously directed a colour feature film or worked for advertising agencies. But both were very committed to political filmmaking. Watkins was associated with left-wing, oppositional politics, particularly The $W$ ar Game (1965), a shocking film about the possible impact of a nuclear attack on Britain that was banned by the BBC from television broadcast. He managed to interest Universal in backing Privilege, probably because it featured pop singer Paul Jones and for its counter-cultural appeal. He later claimed Universal were 'very ambivalent' about the film and eventually withdrew it from distribution. ${ }^{10}$ Levy was drawn to the Greek legend of Herostratus, who reputedly burnt down the Temple of Artemis at Ephesus in 356 B. C. so that he might become famous. He was executed, and thereafter his name was subject to a damnatio memoriae (condemnation of memory) law that forbid mention or record of his name, thus denying him everlasting notoriety. Levy wanted to adapt the legend in the context of the 1960s, and his pitch for a short film won funding from the British Film Institute's Experimental Film Fund. When his vision expanded into a feature film Levy had to secure additional funds and the production was protracted.

In order to analyse both films from a number of perspectives that bring out their engagement with and contribution towards embedding colour within political discourses, a brief narrative outline of each will precede their comparison with reference to issues pertinent to colour analysis and theory. Both narratives involve a young man who is exploited by powerful forces that turn out to be impossible to challenge; by the end, both are back where they started, having failed to exercise their own will against oppressive institutions that crush their individuality. Privilege critiques the world of pop music and its ruthless promotional strategies. It was influenced by Lonely Boy (Roman Kroitor and Wolf Koenig, 1962), a cinema verité-style documentary about pop singer Paul Anka. Watkins was inspired by the hand-held camerawork and attempt to document Anka's more private moments when not performing on stage. ${ }^{11}$ In Privilege Steven Shorter (Paul Jones) is a manufactured pop star who is manipulated by a repressive government in league with the Church 'to deflect rebellious youth from dangerous political activities into sheep-like passivity'. ${ }^{12} \mathrm{~A}$ controlling entourage manages every detail of his public image, and when commercial saturation point has been reached they decide to change it from a rebellious yet controlled figure to one equated with total religious conformity. When Steven revolts against this manipulation his career is halted; he is banned from appearing on television and consigned to obscurity.

Like Watkins, Levy was interested in exploring techniques associated with experimental documentaries, such as non-scripted dialogue and how a film's structure could present 'emotional rhythms' in a 'network of resonances between shots' to achieve Brechtian alienation effects. ${ }^{13}$ In Herostratus Max (Michael Gothard), a desolate, disaffected young poet, plans to end his own life. Hoping that his alienation and social neglect might be publicised as a political act, he approaches advertising executive Farson (Peter Stephens) to exploit his suicide as a media event. Farson agrees and puts in train an exploitative media campaign about the 'event' that subverts Max's original intentions. Just before it is due to take place Max changes his mind after establishing an emotional, 
sexual connection with Farson's assistant Clio (Gabriella Licudi). However, he resolves to go ahead when he learns that she, too, has been manipulated by Farson, and his feelings of despair return. The film ends with Max at a bleak cityscape rooftop where he accidentally pushes another man to his death. There are no crowds, and he disappears into the background: as in Privilege, an individual's attempt to control sinister forces has proved futile.

The rest of this article will compare Privilege and Herostratus in terms of their approaches to themes and techniques that invite colour analysis and theory. Both films involve a key sequence in which an advertisement shoot is replicated; costume and colour construct an obtrusive impact in terms of their variation and commentaries on power and gender; both films play with 'warm' and 'cool' colour symbolism, and they deploy dynamic interactions between lighting, framing and colour. Since Herostratus is more overtly experimental in formal terms than Privilege, it also features some arresting intertextual allusions and techniques, for example, shots that resemble the distorted facial imagery in Francis Bacon's paintings, and the addition of inserts of found documentary footage. Together the films launch radical, hard-hitting appraisals of contemporary advertising aesthetics and political ideologies.

\section{Constructing Parodies of Advertising}

In Privilege Steven has to promote apples in a commercial that is highly lucrative for the company controlling his image. This involves extras dressed as giant apples in an absurdist parody of contemporary advertising used by Watkins to expose and critique the culture of advertising and promotion that surrounds Steven.

The shoot for the apple commercial takes place in a rural location, and a close-up of luscious-looking, red-tinged, shiny ripe apples on a tree precedes shots of actors with the bulbous 'apple' costumes surrounding their torsos. As the sequence documents the advertisement being shot, it contains strong self-reflexive, satirical elements that exaggerate the out-of-proportion effort that goes into making the commercial for a basic, natural product, including stills being taken as a record of the shoot, and an interview with the pretentious director who claims to be inspired by existentialism, exhorting the extras to 'think apples, be apples and ultimately become apples'. The commercial casts Steven as a Medieval chivalric knight, wearing a square-patterned blue and silver tabard over a silver armour frontispiece, who is rewarded with the gift of luscious apples by a maiden dressed in a flowing, white costume and headdress with golden embellishments. A close-up shows him staring straight to camera as he bites an apple, followed by an emblematic shot of the entire scene with daffodils and tulips completing the pastoral ensemble. Parodic impact is heightened by the ways in which the sequence slips between documenting and demonstrating the apple commercial.

In terms of colour, the sequence foregrounds the importance of shiny, glossy surfaces for a natural product that is being advertised. Gloss makes colours look more saturated and brilliant, depending on the intensity of reflected light and surface properties. Not only are the apples glossy, but so is Steven's tabard, with its sparkling silver squares, and the jacket worn by the director is striped with shades of blue and is made of shiny, synthetic material that glistens in the light. This visualises an association between advertising, surface values and glossiness, linking with the film's theme of the commodification of Steven who becomes the ultimate product exploited for commercial ends. The importance of glossiness in heightening the effect of colour constancy is demonstrated, an important feature of advertising aesthetics since it encourages viewers to 
perceive objects as undifferentiated: the apples are all perfect, so is Steven and the commercial. ${ }^{14}$ Fredric Jameson notes how glossiness prevents objects from being perceived as unique, instead creating 'a unified display and transferring, as it were, the elegant gleam of clean glass to the ensemble of jumbled objects - bright flowers, sumptuous interiors, expensively groomed features, period fashions - which are arranged as a single object of consumption by the camera lens'. ${ }^{15}$ The final image of the advertisement, with Steven dressed in his Medieval costume, accompanied with the apples and flowers, illustrates precisely this point, giving weight to the film's commentary on the use of colour and texture in the aesthetics of advertising that are to be consumed, as Jameson puts it, 'as images rather than as representations of something else'. ${ }^{16}$ The total effect is to unite Steven, the product (apples) and setting (pastoral scene) into an unambiguous commercial address.

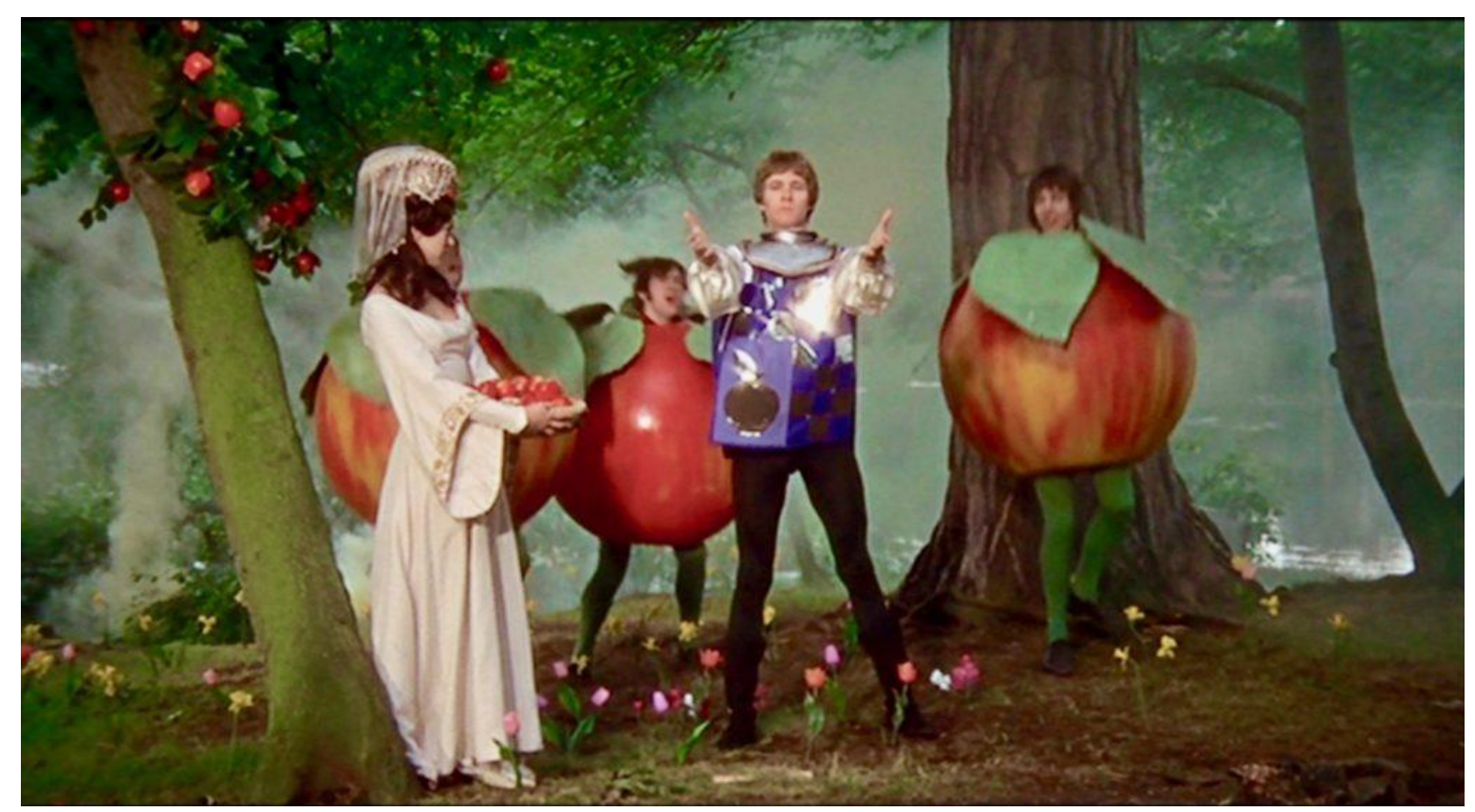

Figure 1: Still from Privilege (Peter Watkins, 1967)

The sequence is, however, more complex in the context of the logic of the entire film, rather than the advertisement, because Steven is becoming aware of his exploitation. Just before the commercial shoot, his recent American tour is being discussed by his managers. It had lasted 25 days, involved 64,700 miles of travel, 64 appearances, fourteen television slots, nine charity functions, but with only three days off. To protect their investment, they are concerned that Steven is becoming 'nervous and withdrawn', and this is shown in his disaffected expression between shots for the commercial, and also a glimmer of defiance when he bites into the apple. 


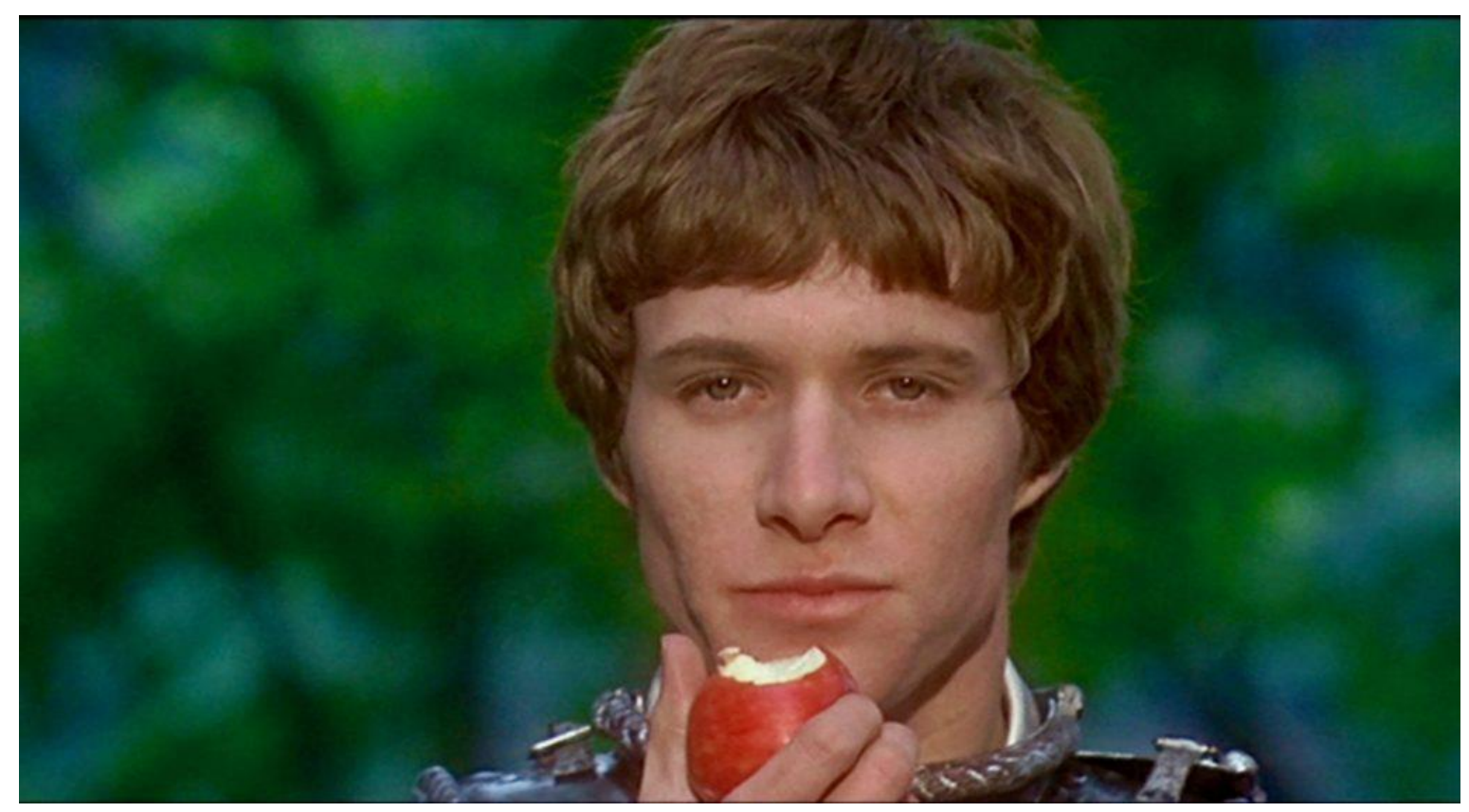

Figure 2: Still from Privilege (Peter Watkins, 1967)

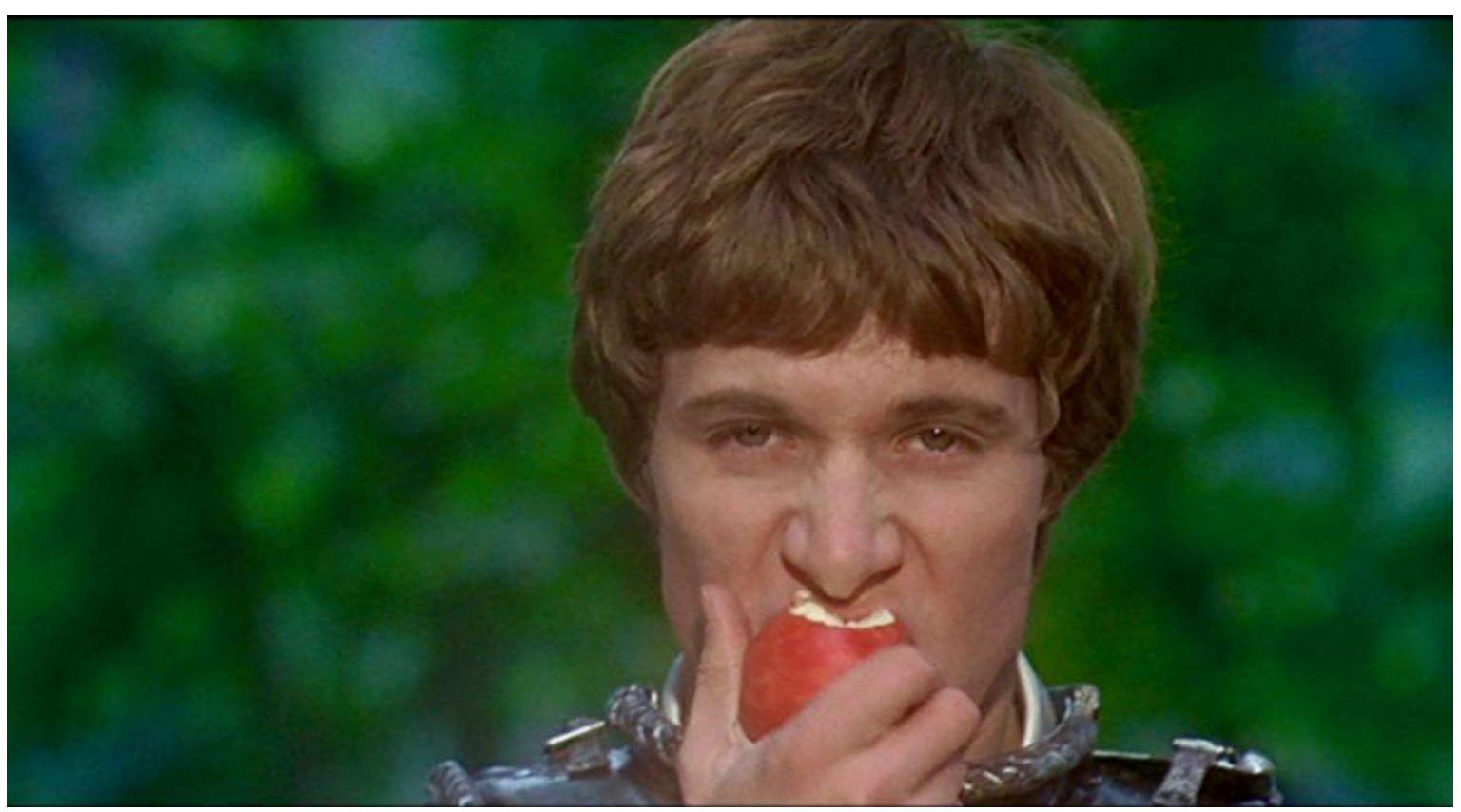

Figure 3: Still from Privilege (Peter Watkins, 1967)

Watkins stated that: 'In the figure of the young man, the film is dealing with a kind of psychic anxiety and psychic tension of many young people who... are very conscious of this manipulation process'. ${ }^{17}$ This aspect of self-reflexivity offsets the overall effect of constancy. In this case, the film's narrative influences our perception of Steven, despite his placement in the advertisement, as a person craving individuality; his struggle for uniqueness and depth challenges the uniform, glossy veneer with which he is otherwise associated. The structuring of the advertisement in this way creates emotional tension that offsets the commodification processes it has nevertheless presented. 
Though rendered very differently, the advertisement sequence in Herostratus also delivers a withering critique. After Farson has accepted Max's highly unusual proposition, he permits Max to stay in a large advertising studio which contains cameras and props, including a bed in the centre. Shots of Max alone in the studio are then intercut with black and white footage of world leaders' speeches at the end of the Second World War, including President Truman's speech to the United Nations articulating hopes for 'a just and lasting peace', which is followed by a succession of inspiring speeches by other politicians calling for social justice. The last image, however, is of a rocket taking off, exploding instantly and bursting into flames, perhaps signifying that post-war optimism has not been realised. Levy considered this particular image as exemplary of 'pure cinema' because of its placement within an associative sequence of 'montage, plan sequence, dynamic composition, rhythm, colour, pictorial counterpoint, textures, distortion etc'. ${ }^{18}$ In this way the sequence builds its argument within a framing structure that is overtly political, gesturing to theories of montage.

A colour shot of Max on the bed, combing his hair and looking into a hand mirror, is followed by black and white footage of famous film stars and models being photographed. When we return to Max, he is cutting up a photograph of a model, the scissors tearing through the eye, an action which has cinephile allusions to the opening shot of Luis Buñuel's avant-garde classic Un chien andalou (1929) as a quite literal disruption of conventional ways of seeing. This is followed by a series of close-ups of other advertisements he has cut up, a montage of surreal, collaged images which have been manipulated in the style of Pop Art. Some of the images are black and white but with colour features added, and vice-versa, for example an eye looking out of a mouth and unproportionally large, red lips pasted on a photograph of a woman's head that has disturbingly been collaged into a cooked leg of meat. This particular image anticipates a later montage that links women with meat.

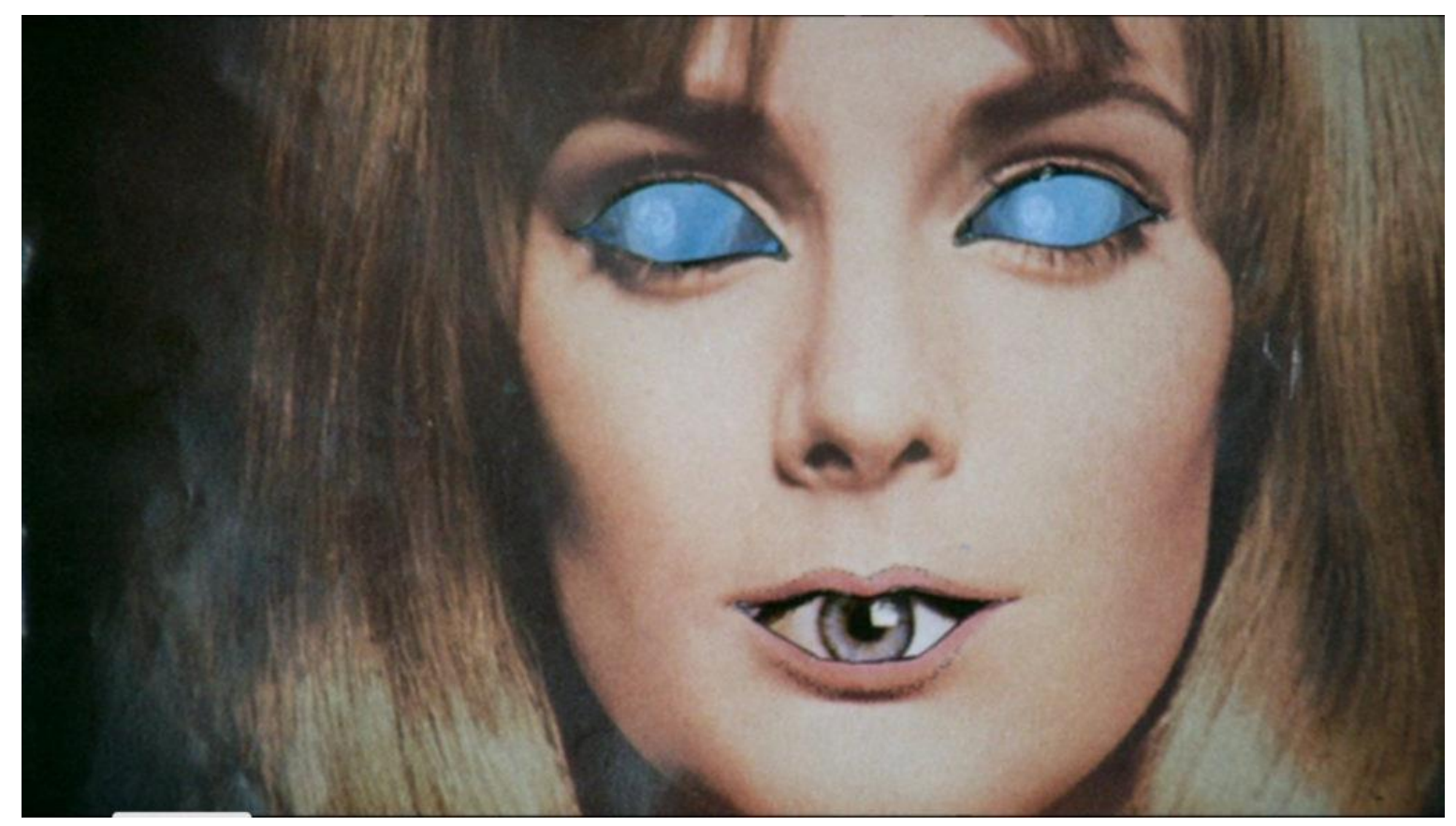

Figure 4: Still from Herostratus (Don Levy, 1967) 


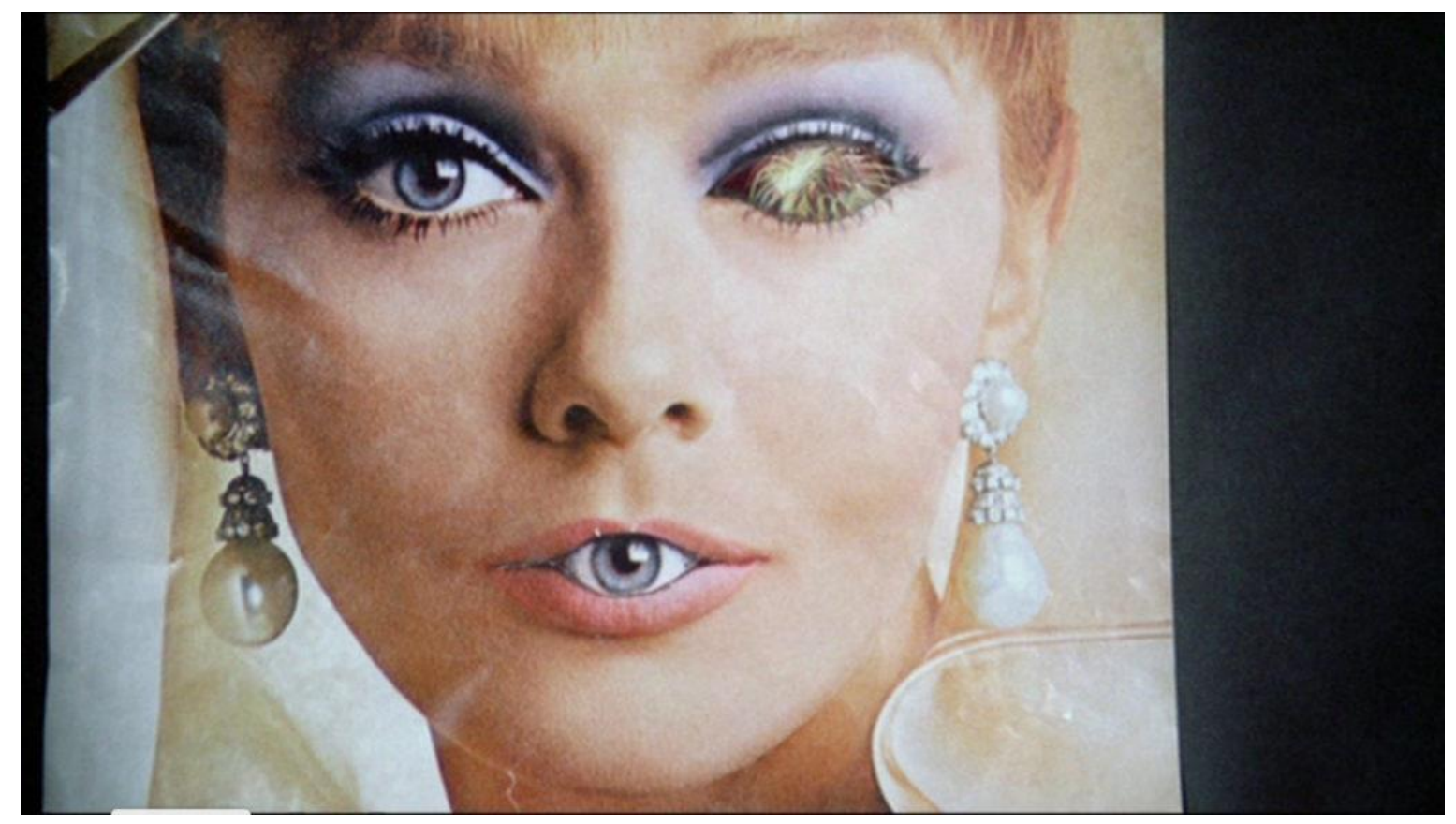

Figure 5: Still from Herostratus (Don Levy, 1967)

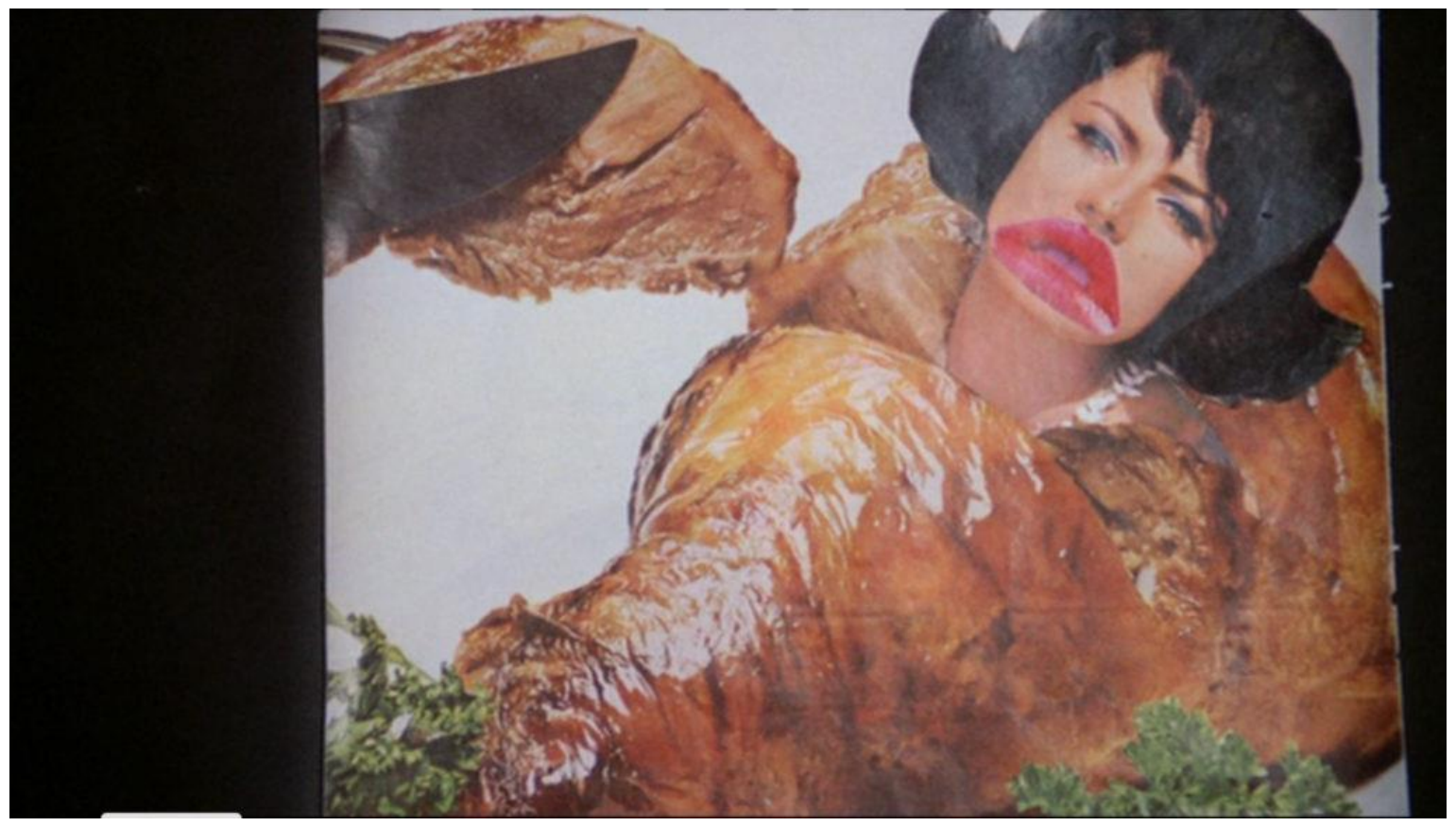

Figure 6: Still from Herostratus (Don Levy, 1967)

This animated montage (the additions appear as animated features) de-familiarises the advertisements, their strangeness constituting a surreal interlude that is perhaps an expression of Max's desire to control the personal situation he is now encountering as the process to 'manage' his public suicide begins. As he can transform the glossy advertisements into surreal artworks, at this point he is hopeful that publicising his own death will be a process he can influence and direct. Presenting an association between women and meat quite literally in a single image is also a mode of politicised discourse/imagery, a re-contextualising technique used in different contexts by filmmakers including Buñuel and Godard. ${ }^{19}$ 
The sequence proceeds with a close-up of a blonde-haired woman's face (Helen Mirren), with a pink light on the set partially illuminating her hair. The camera moves down her body to show in close-up her costume: a heavy and shiny, ribbed pink coat, long black gloves, black fishnet tights, patent leather heels and a black corset patterned with shiny, pink flowers with sequin details. She says: 'Do you want me?', and 'if you do, there's something you've got to get for me'. The pink light shines on different parts of her body as she turns and poses, while the dynamic camera deploys emphatic moves such as a low-angled shot that then zooms into a close-up of her face which becomes totally infused by the artificial pink light. Her playful dialogue lists some quirky, salacious options before she reveals that what she really desires is to be bought a brand of shiny and orange rubber washing-up gloves. She then throws up her arms to show that she is wearing them, describing the gloves as 'smooth on the inside, they're absolutely leak-proof; use them for all your dirty work!' as she caresses her body. The sequence concludes with Max carrying the woman off, disrupting the performance and protesting 'that was rubbish'. By this time the studio and filming equipment are visible, making clear that the sequence has indeed been an extremely exaggerated, playful television advertisement for rubber gloves. Max's intervention is not part of it, signalled by the wild, frenetic change in style of shots that, we surmise, accidentally capture the disruption.

As with Privilege there is an emphasis on glossy surfaces, superficiality and performance, but the commentary on advertising is even more imbued with its radical critique. The way the sequence is framed, between the shot of Max looking into a mirror, and his rescue of the woman once the advertisement has concluded, implies that he is attempting some sort of control over the world he has joined. Like Steven, he seeks individual agency, but at this point Max is less aware that this is impossible. His collages shatter the seamless impact of the glossy magazines; the objects are far from the 'unified display' of the 'single object of consumption' identified by Jameson in his discussion of glossiness. The woman's performance could be seen as a feminist parody of advertisements for household products; it is as if she is advertising her body as well as the gloves, while drawing attention to the often extremely absurd scripts used to advertise products. As Laura Mulvey comments, the female image in advertising did not necessarily refer to women in everyday life but 'to an image that could be put into circulation as part of commodity culture, and as part of the general commodification of society'. ${ }^{20}$ Other feminist criticisms of advertising draw attention to stereotyping, and the sexualisation of women advertising domestic and other products. ${ }^{21}$ The orange colour of the gloves is significant because it was the first available colour from Marigold (although not named in the sequence), a British company that began manufacturing rubber gloves in 1947. Rubber gloves, designed for household use, have historically been identified with women and beauty merchandise for keeping hands soft, and to render invisible the harsh physical effects of housework, as indicated in Playtex's advertisement for gloves in 1959 that assured customers: 'You can have lovelier hands in 9 days'. Even contemporary advertising for Marigold gloves reflects this pitch with a bare-armed woman in a black polka dot dress with a red polka dot bow in her hair demonstrating yellow gloves. 


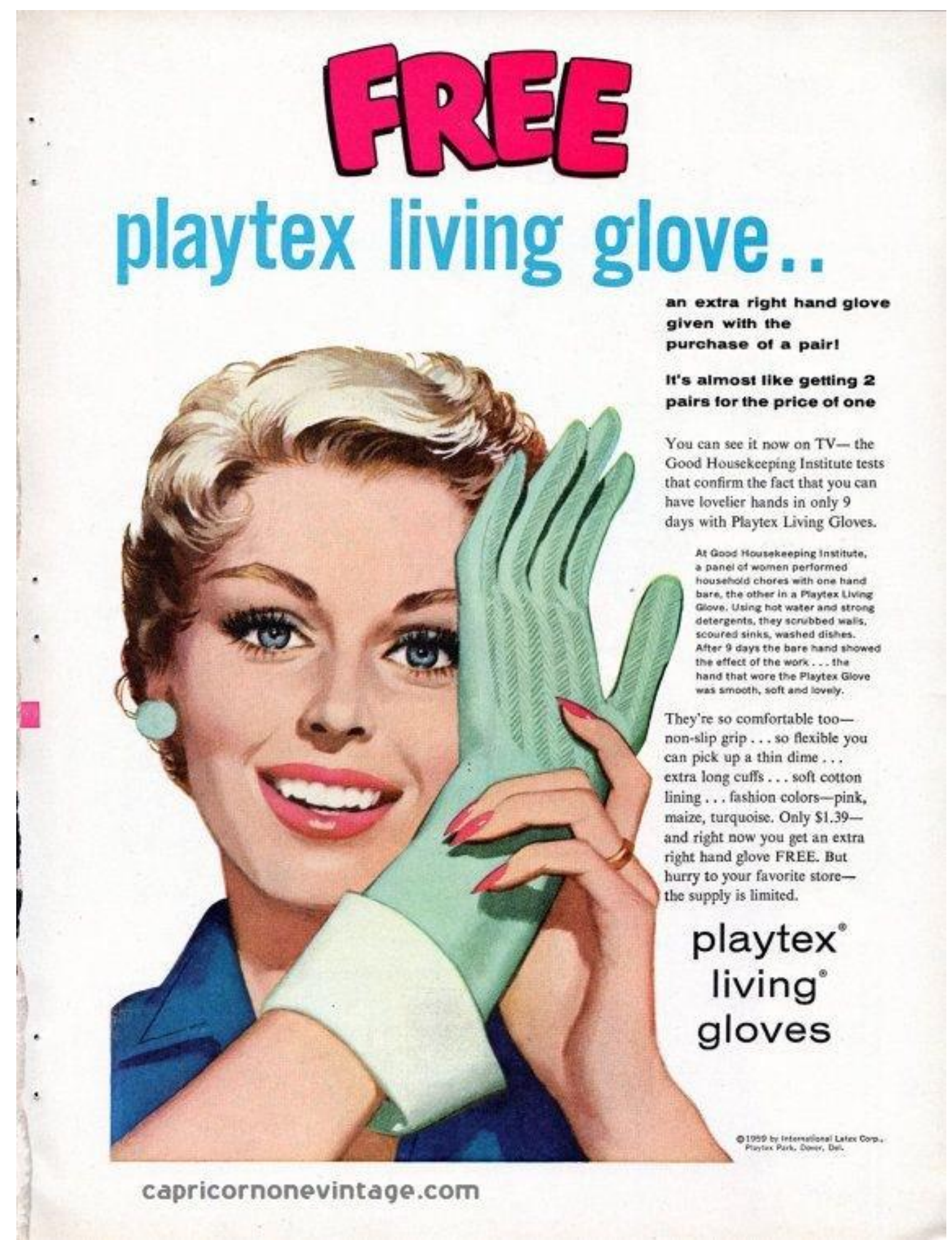

Figure 7: Playtex's advertisement for gloves, 1959 


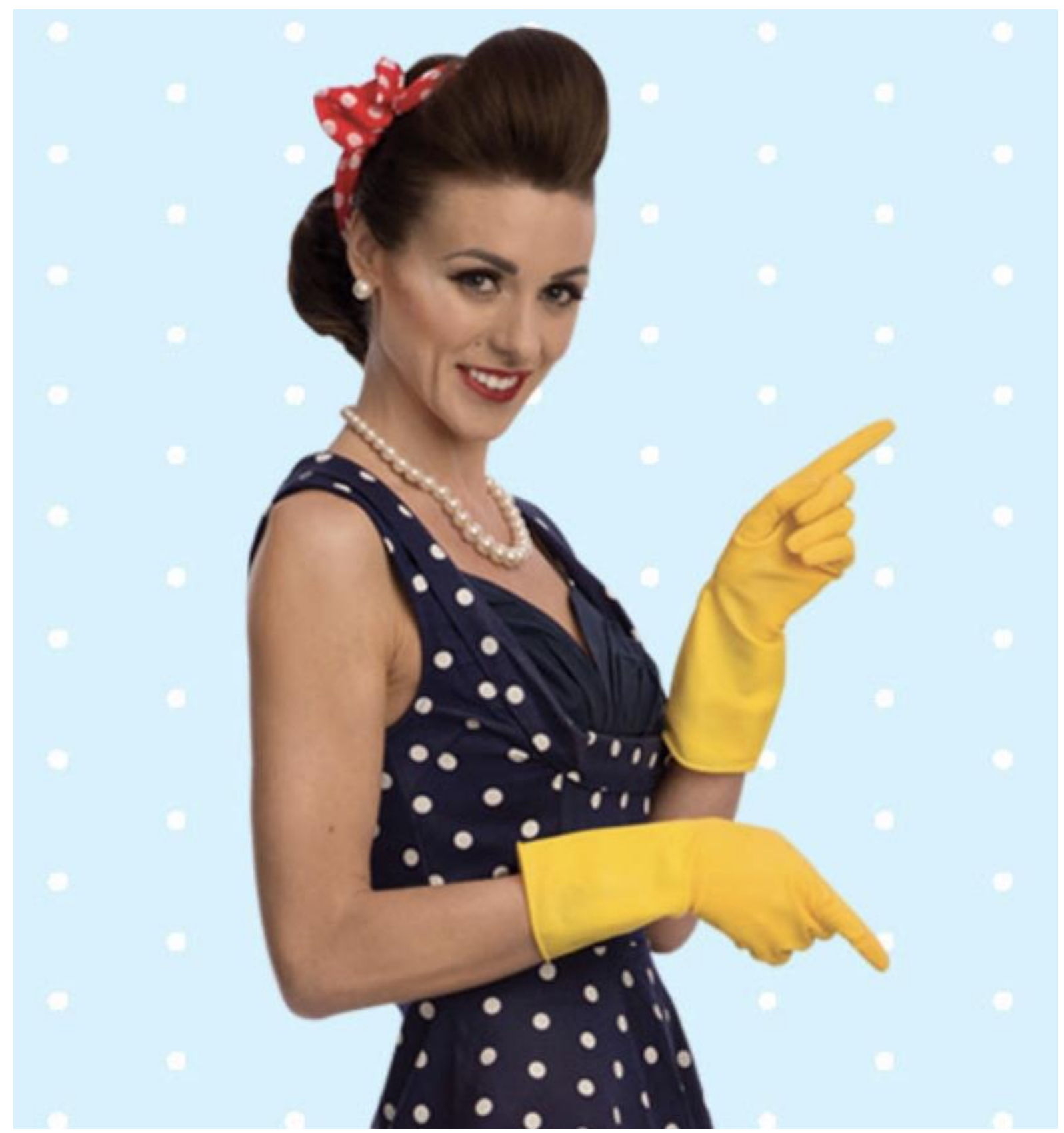

Figure 8: Contemporary advertising for Marigold gloves.

The primary association in this strange, sexualised sequence in Herostratus is however fetishism in a double sense: the gloves are commodified by being presented as objects of desire, and the woman's body is objectified in their presentation. 


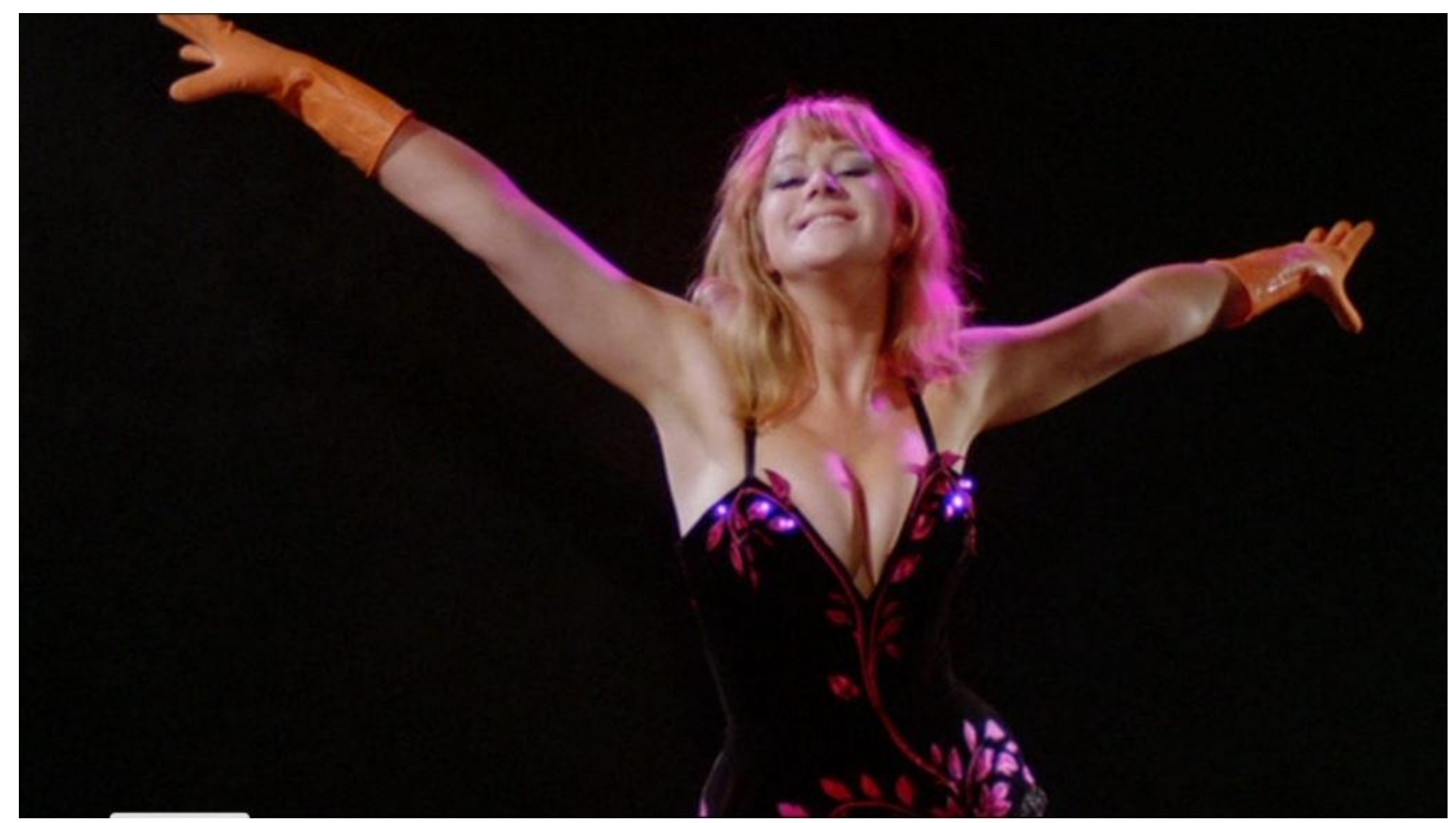

Figure 9: Still from Herostratus (Don Levy, 1967)

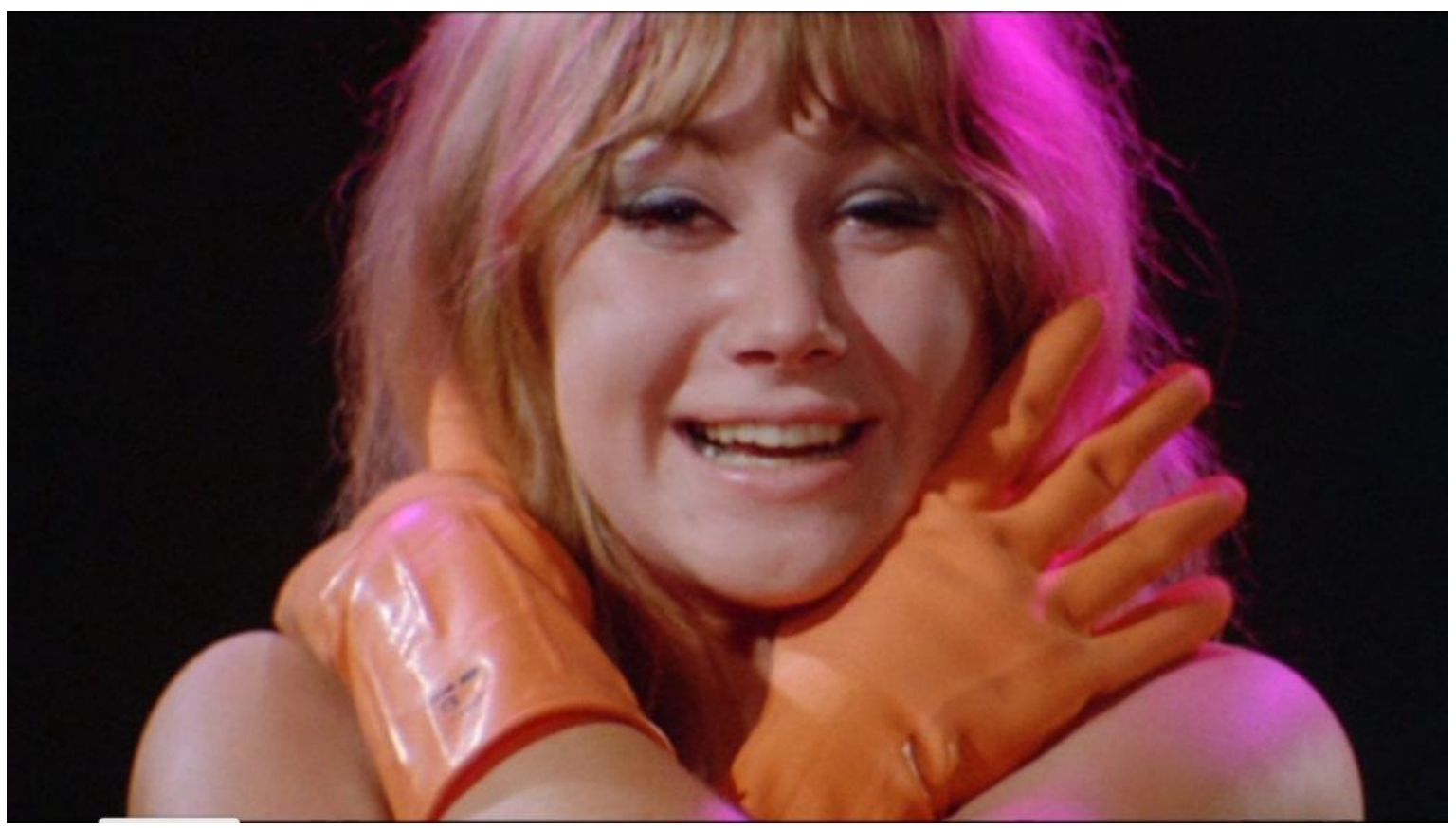

Figure 10: Still from Herostratus (Don Levy, 1967)

This representation can be linked to criticisms by contemporary psychologists concerning the sexualisation of advertising products such as cigarettes. ${ }^{22}$ It uses the conventions of glossy, surface colour but in a masquerade of sexualised femininity that draws attention to that very construction. ${ }^{23}$ The orange of the gloves introduces an on-trend colour while creating a stark contrast to the blacks and pinks of the woman's costume. ${ }^{24}$ The gloves' synthetic appearance also de-naturalises her hands and arms, and is reminiscent of Max's disturbing collaged advertisements. The vivid pink light, a key signature for the sequence, exhibits a 'transitory luminosity' associated with bright colours: it is never stable, ranging over the woman's body before totally enveloping it. 


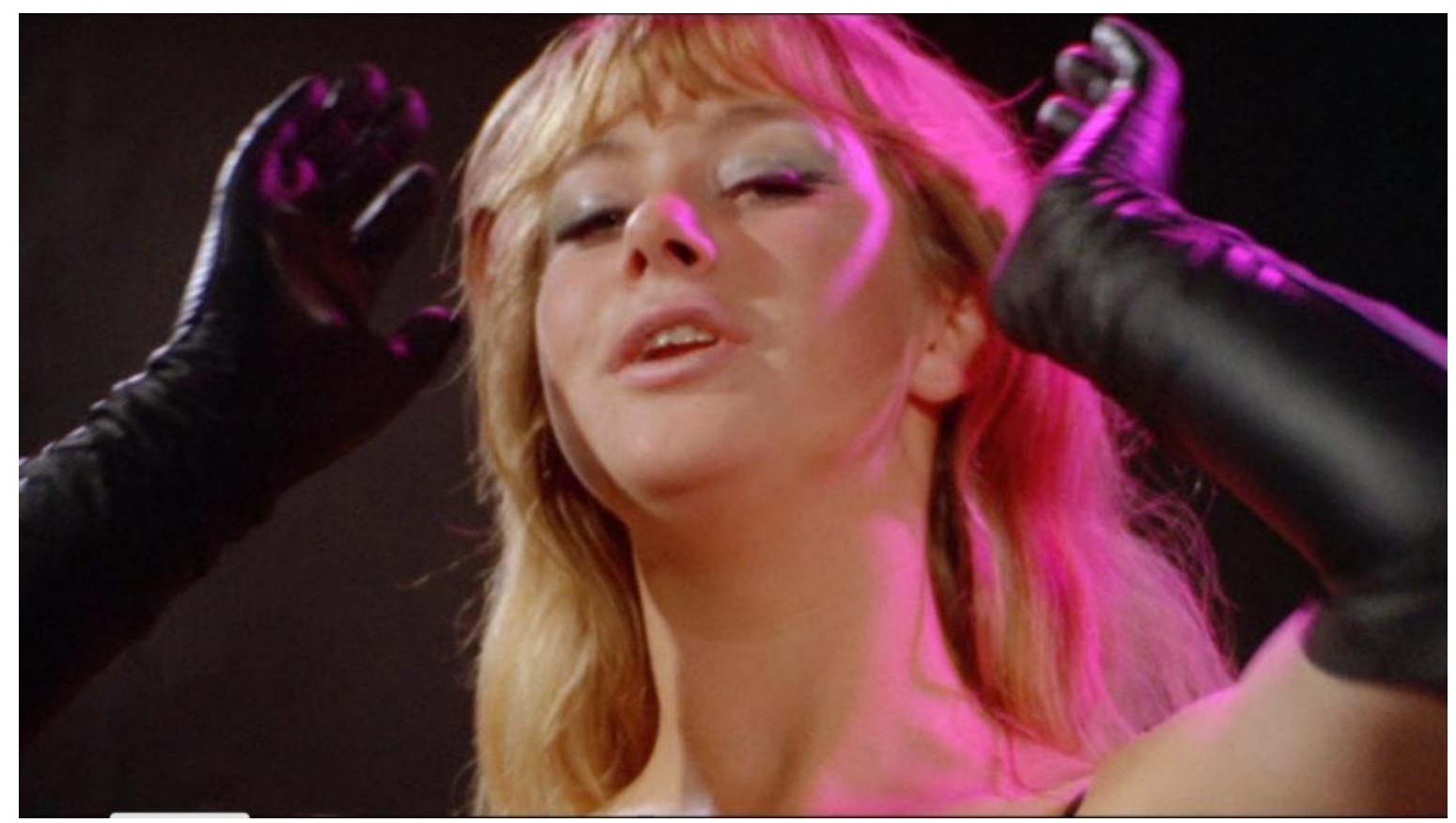

Figure 11: Still from Herostratus (Don Levy, 1967)

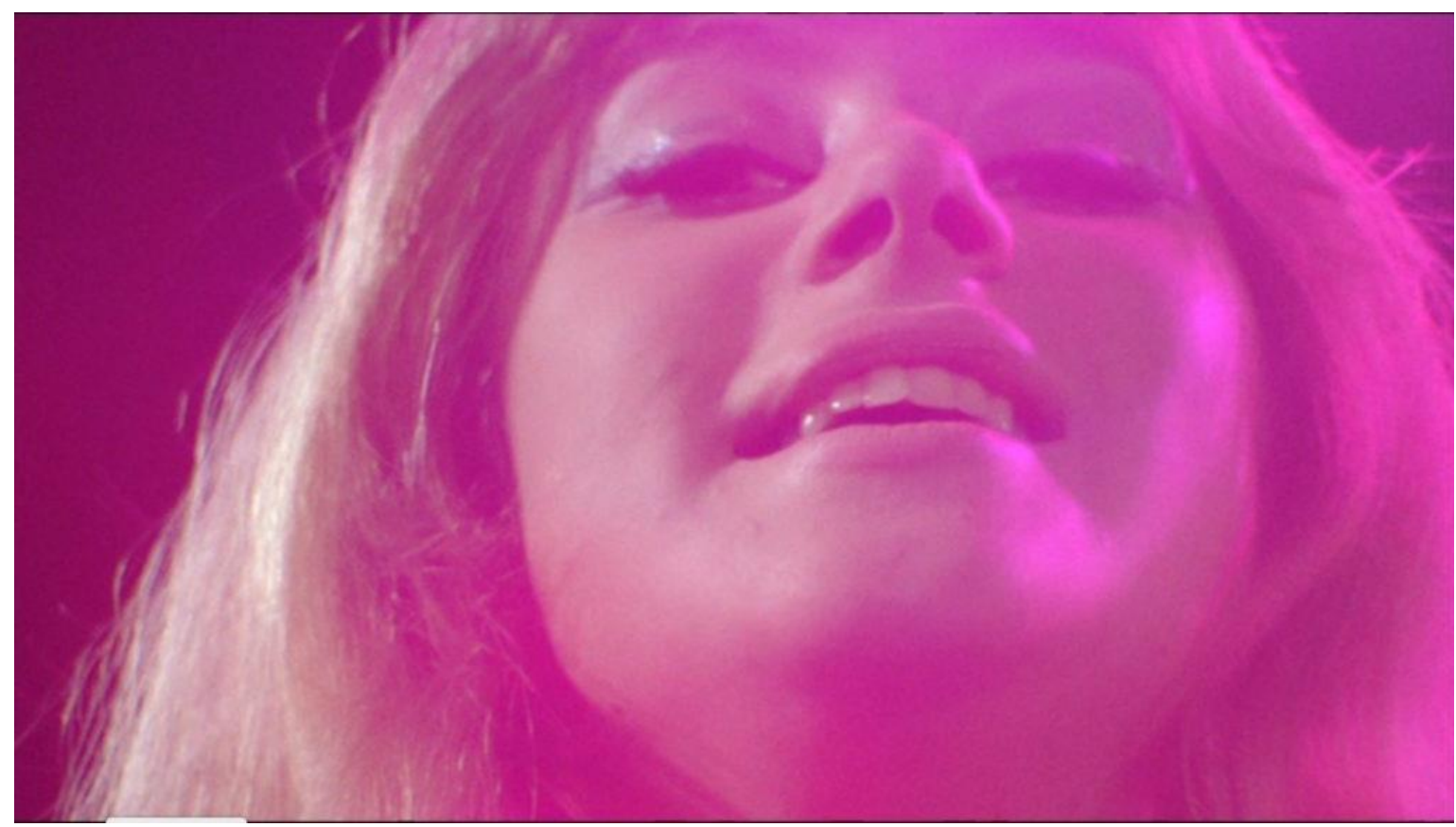

Figure 12: Still from Herostratus (Don Levy, 1967)

The latter can be read as an attempt to unify the image, with the woman subsumed by the artificiality of the pink's glossy, synthetic veneer. As shown in Grisard's study of pink and gender, since the mid-1950s the colour was marketed particularly aggressively for younger women consumers while reinforcing 'the infantilization of adult women's fashion, on the one hand, and the heteronormative feminization and sexualization of the girl child, on the other' ${ }^{26}$

Seeing the film in the present day invites intertextual reference to the casting of Helen Mirren, esteemed British actress, in one of her first film roles. As noted above, her masquerade is an exaggerated parody of contemporary advertising that, however, reflects, within the film's diegesis, the kind of work undertaken by Farson's agency. Max's impression of what he has seen 
in the studio is disturbing as an unknown model gives a hyper-sexualised performance to advertise a mundane household item: the pink and orange colours are central in glamorising that very fact. As in Privilege, the sequence's parody of contemporary advertising combined with the viewpoint of an alienated character, creates a space for politicisation as the conventions of advertising are presented, exposed and critiqued.

\section{Costume, Colour and Power}

The main protagonists of both films are directly marked by advertising: in Privilege Steven is the vehicle for promoting the state's propaganda, and in Herostratus Max is a new prospect for Farson's agency. In Privilege costume is accorded a key role in delineating the different phases of Steven's public image which is underscored by a major colour shift from blue to red. At the beginning of the film, on his return to Birmingham after a successful world tour, Steven wears blue, complete with blue insignia and other coded promotional materials. Shot from a low camera angle, he is presented as a triumphant warrior returning from battle.

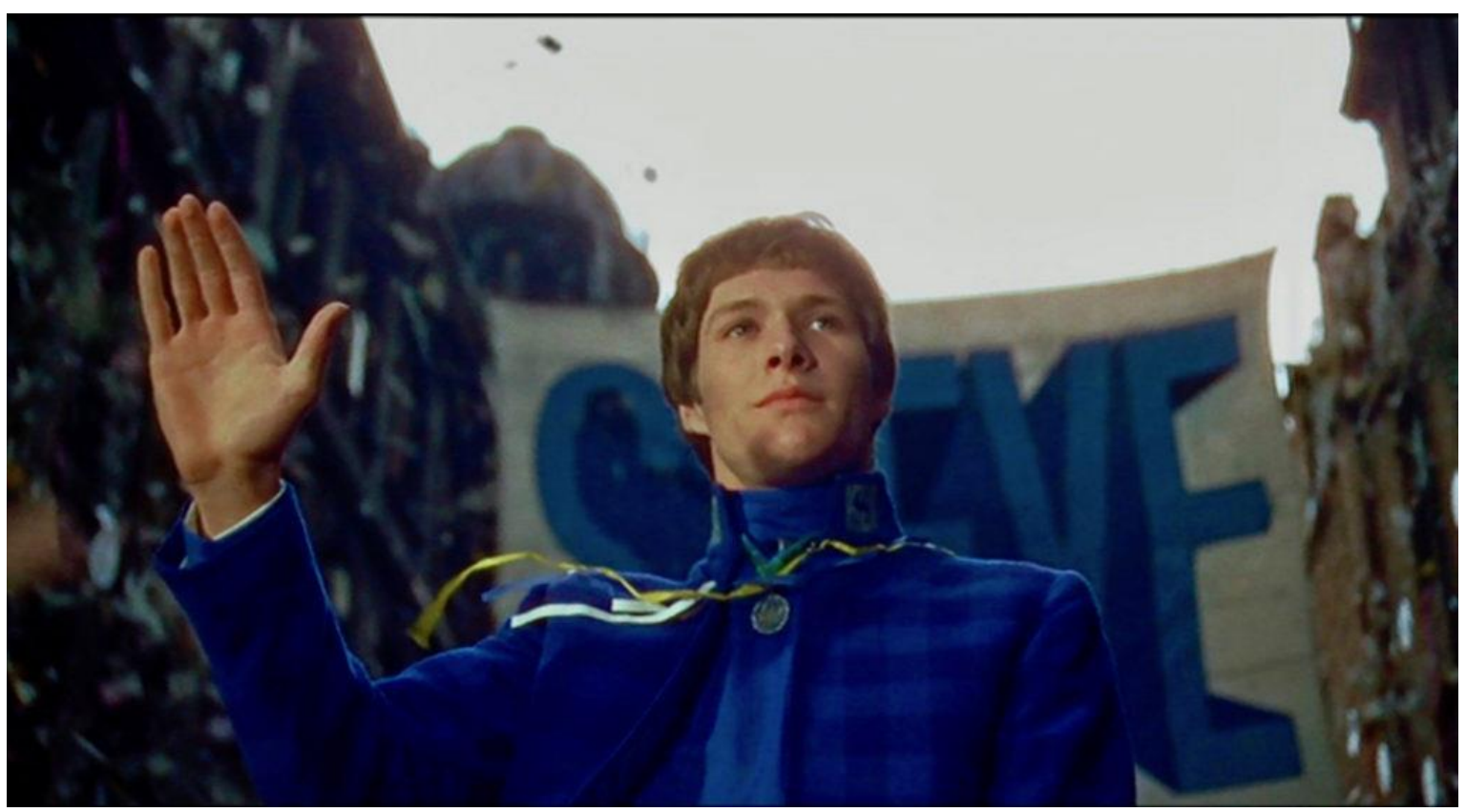

Figure 13: Still from Privilege (Peter Watkins, 1967)

The welcome parade is filmed as reportage, the voice-over informing us that Steven's stage act, during which he is imprisoned in a cage and in a song implores the audience to set him free, is designed to provide the public with 'nervous release from all the tension caused by the state of the world'. The following sequence satirises his motley management entourage who exploit his popularity through intensive publicity campaigns which have turned him into a lucrative marketing vehicle. The 'Steve Dream Palace', a huge silver dome decorated with advertisements for Stevenbranded products, is a prime example. We are told in voice-over that there are 300 such 'Palaces' in Britain, each designed to 'keep people happy and to buy British'. As the camera tracks around the dome we see multiple images of Steven, one with a handful of cash, while we hear that 'when you're buying in here, you're buying Steven Shorter'. A shot of the promotion being 
photographed once again shows Steven's dejection, capturing a private moment that contrasts with his upbeat public, poster image.

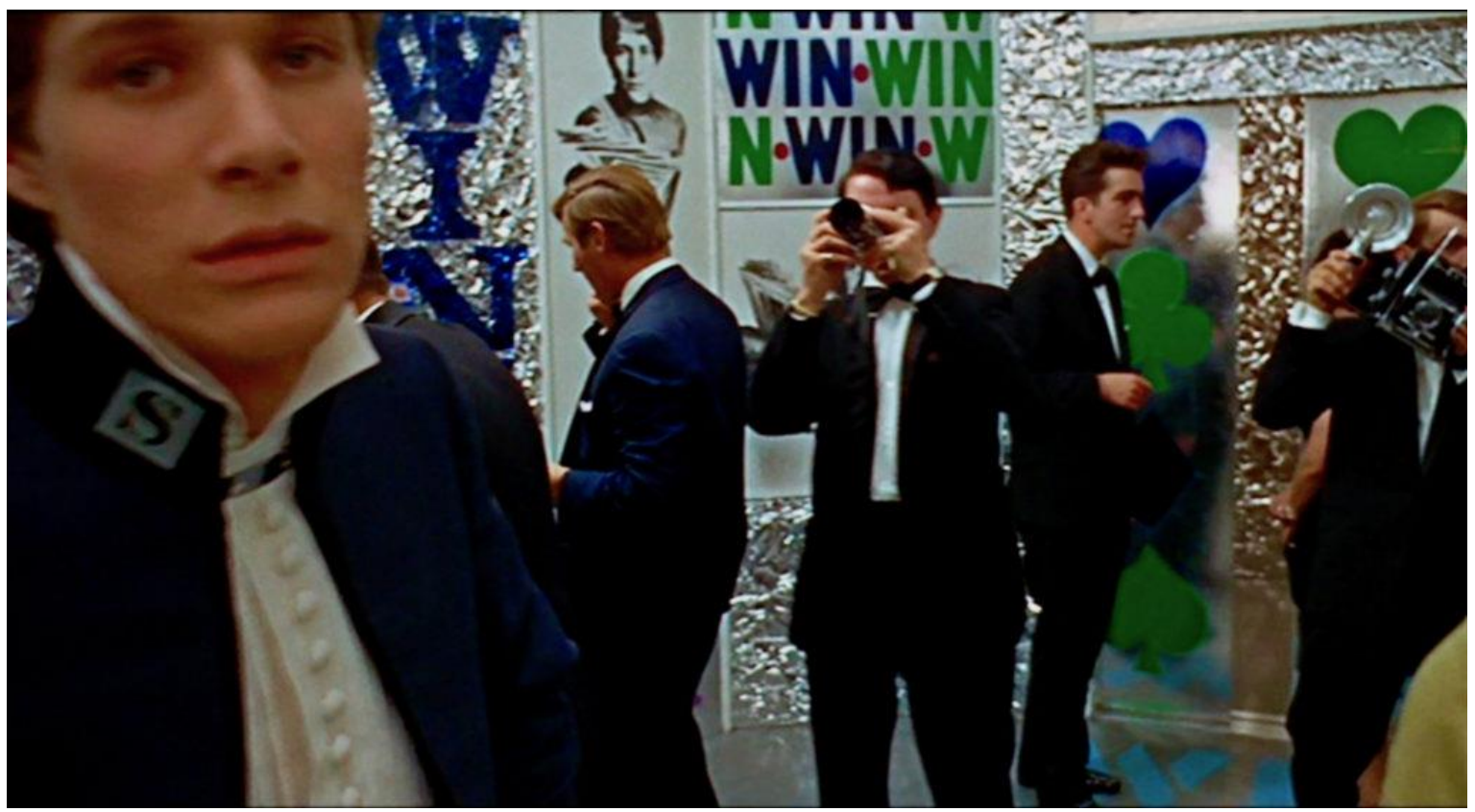

Figure 14: Still from Privilege (Peter Watkins, 1967)

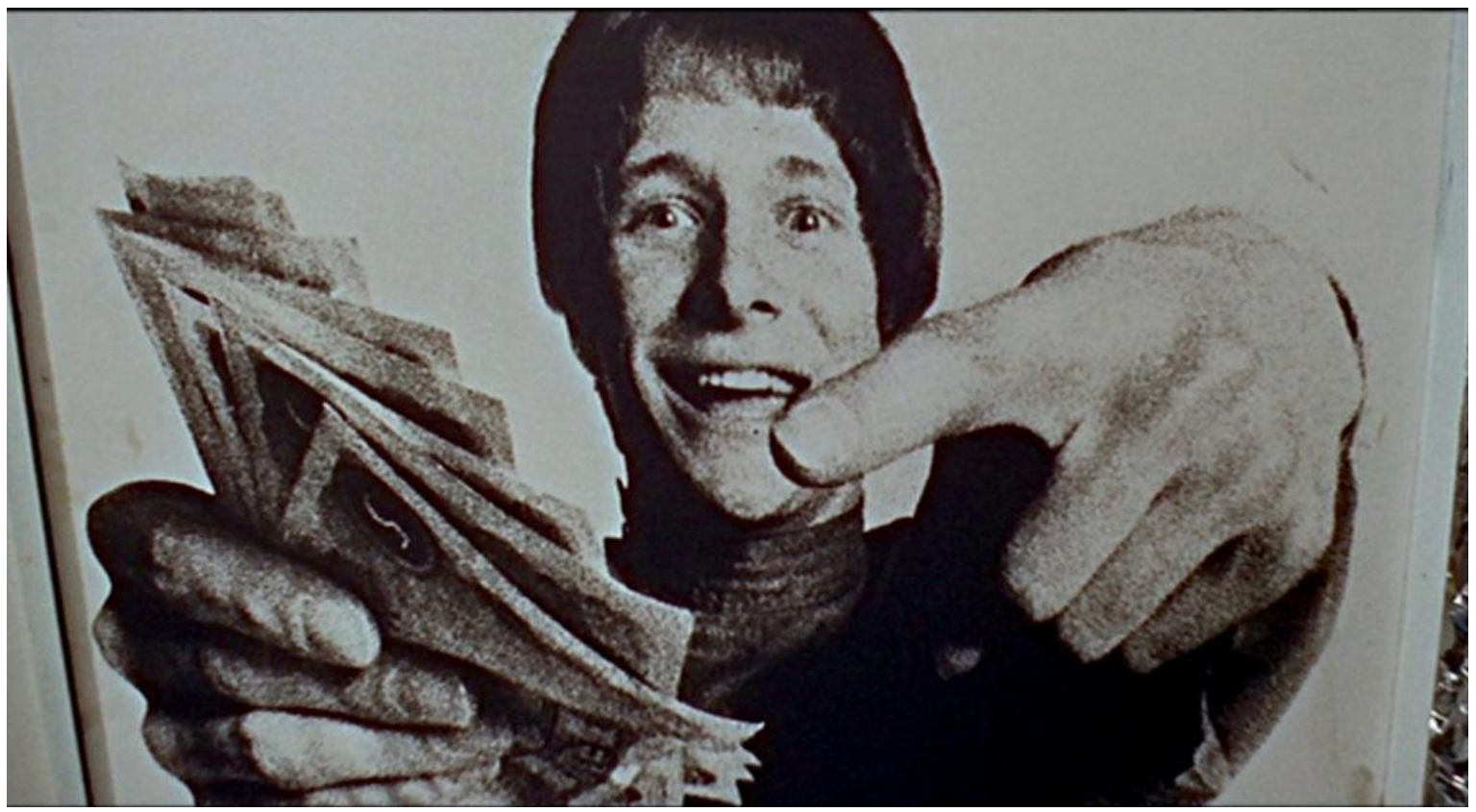

Figure 15: Still from Privilege (Peter Watkins, 1967)

This strategy dissociates word from image, creating tension between Steven's public image and personal experience.

Deciding that 'commercial saturation point' has been reached, the authorities decide to instigate a change in Steven's popular image so that he explicitly represents conformism and religious interests. The switch can be related to monitoring and trend forecasting that typifies the temporalities of advertising and marketing. ${ }^{27}$ To signal the change, a fashion designer demonstrates 
a new range of yellow and white clothes to indicate 'respectability, social grace and above all a newfound innocence'. To make Steven stand out red is chosen as his new signature colour when he is re-presented as a messianic figure who 'belongs to the world'.

The choice of blue for the first part of the film is interesting, especially in view of its contrast with the red chosen for his subsequent conformist image. In spite of its associations with being a 'cool' colour, blue has also been described as being less symbolically marked than other colours because it is 'not aggressive and violates nothing; it reassures and draws together'. ${ }^{28}$ This is appropriate since the segment of the film coded blue links to Steven's image as serving a public, regulatory purpose regardless of his emotive caged-prisoner stage act. The branding for his merchandise and clothes further identifies him as a product - he is Blue rather than an individual, his costume resembling a uniform branded with ' $S$ '. Such details make visible what Watkins referred to as 'media totalitarianism' in which 'the media uses so-called counter-revolutionary movements, methods and songs, and then simply packages them up and regurgitates them to the young, ${ }^{29}$

Red is, however, used to underscore the even more aggressive, emotive and explicitly politicised campaign designed, somewhat ironically, to inculcate conformism with the regime. In view of this, the intermediate yellow fashion campaign can be seen to anticipate its successor, suggesting a contextual link between the two colours that can sometimes occur, as Faiers notes: 'Yellow has an affinity with nature, for example sunshine, but also an accompanying elemental potential for harm that matches red's easily understood incendiary power' ${ }^{30}$ This 'incendiary power' is particularly displayed in a massive concert at a national stadium in Birmingham to showcase Steven's new image. The staging of its propagandist drive for religious ecumenicalism masks more sinister, nationalist interests. The show resembles a Nazi rally, with its plethora of insignia, flags and messianic speeches to huge crowds, and Watkins recalled being influenced by Leni Riefenstahl's Third Reich propaganda films for this sequence. ${ }^{31}$ Its use of vivid, coloured lighting effects can be related to the staging of contemporary rock concerts and multimedia events such as 'The 14 Hour Technicolor Dream' held in the Great Hall of Alexandra Palace, London in 1967 which featured spectacular artificial, coloured light shows and strobe effects. A rock version of 'Jerusalem' is suffused with frenetic red and pink lights that give the impression of a frenzied, communal psychedelic experience designed to increase anticipation for Steven's appearance. A hand-held camera follows him as he emerges from a tunnel into the stadium, his red attire increasingly dominating the frame as he runs through the crowds, and a barrage of intermittent camera flash bulbs further de-stabilises the image. Finally, he is shown with his face illuminated by a deeply saturated red, as if the colour has absorbed his entire body.

Watkins considered this sequence to be very effective from a colour perspective: 'The boy is dark, and there is a kind of red haze over the whole thing. I think there is a psychic tension there which is very powerful'. ${ }^{32}$ 


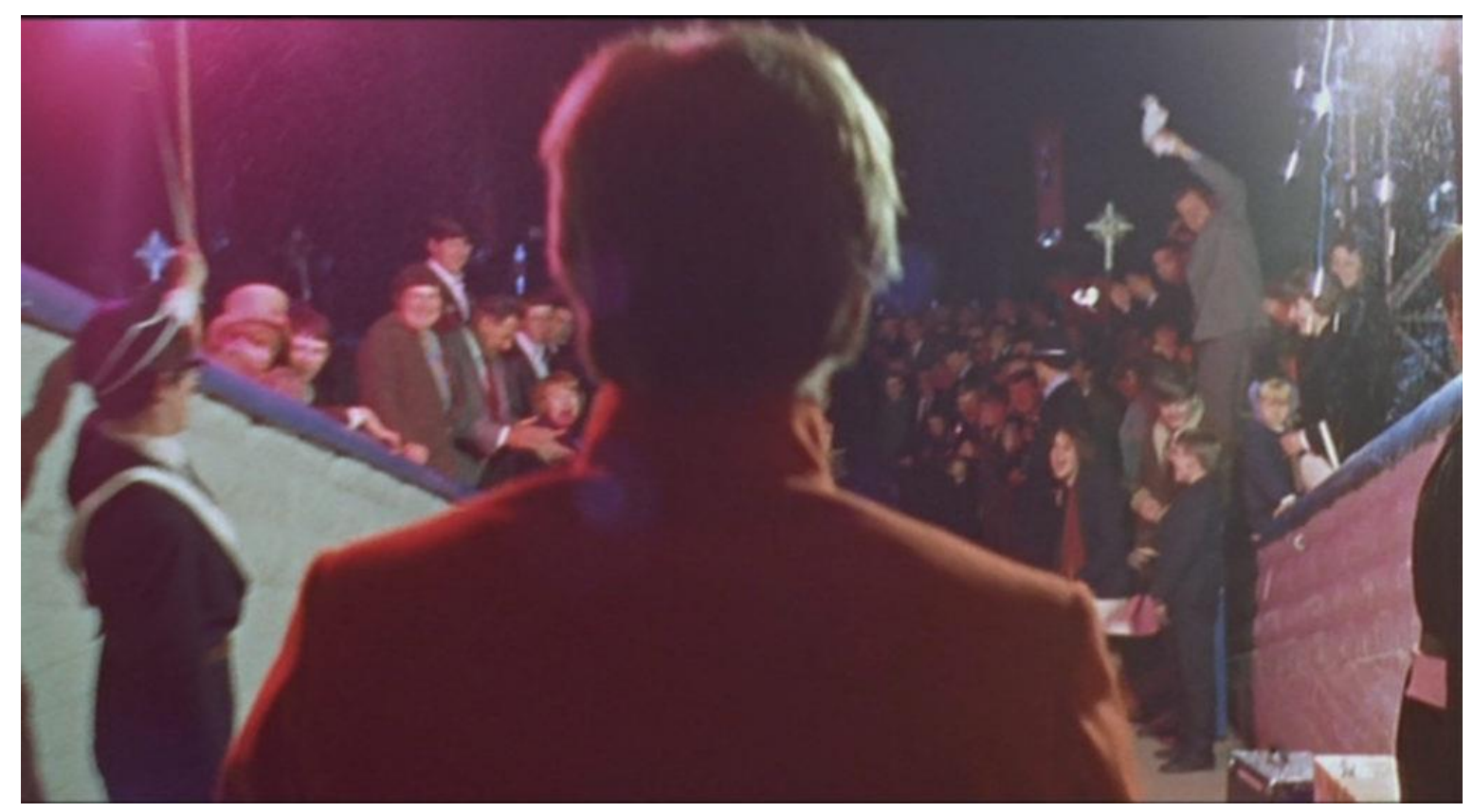

Figure 16: Still from Privilege (Peter Watkins, 1967)

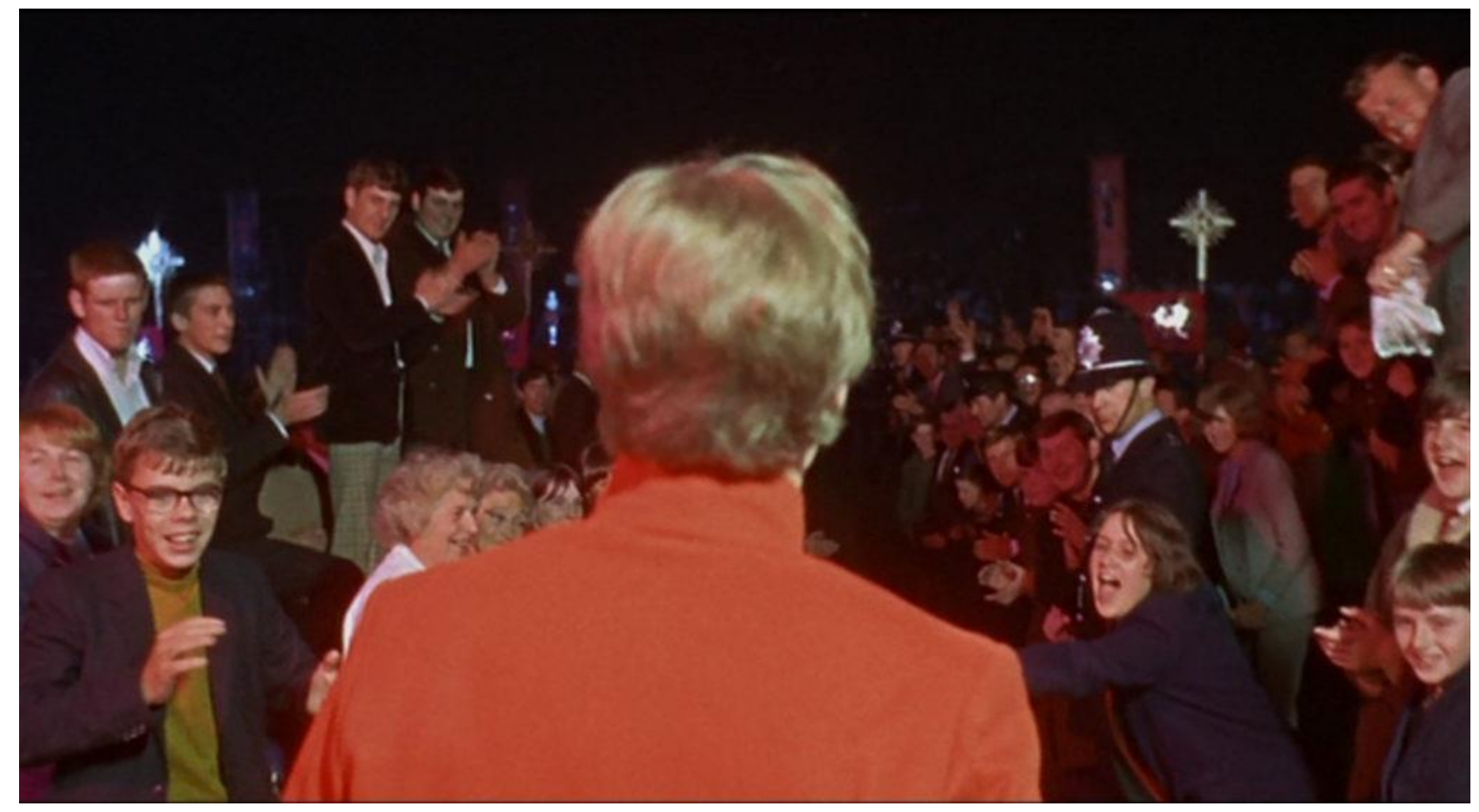

Figure 17: Still from Privilege (Peter Watkins, 1967) 


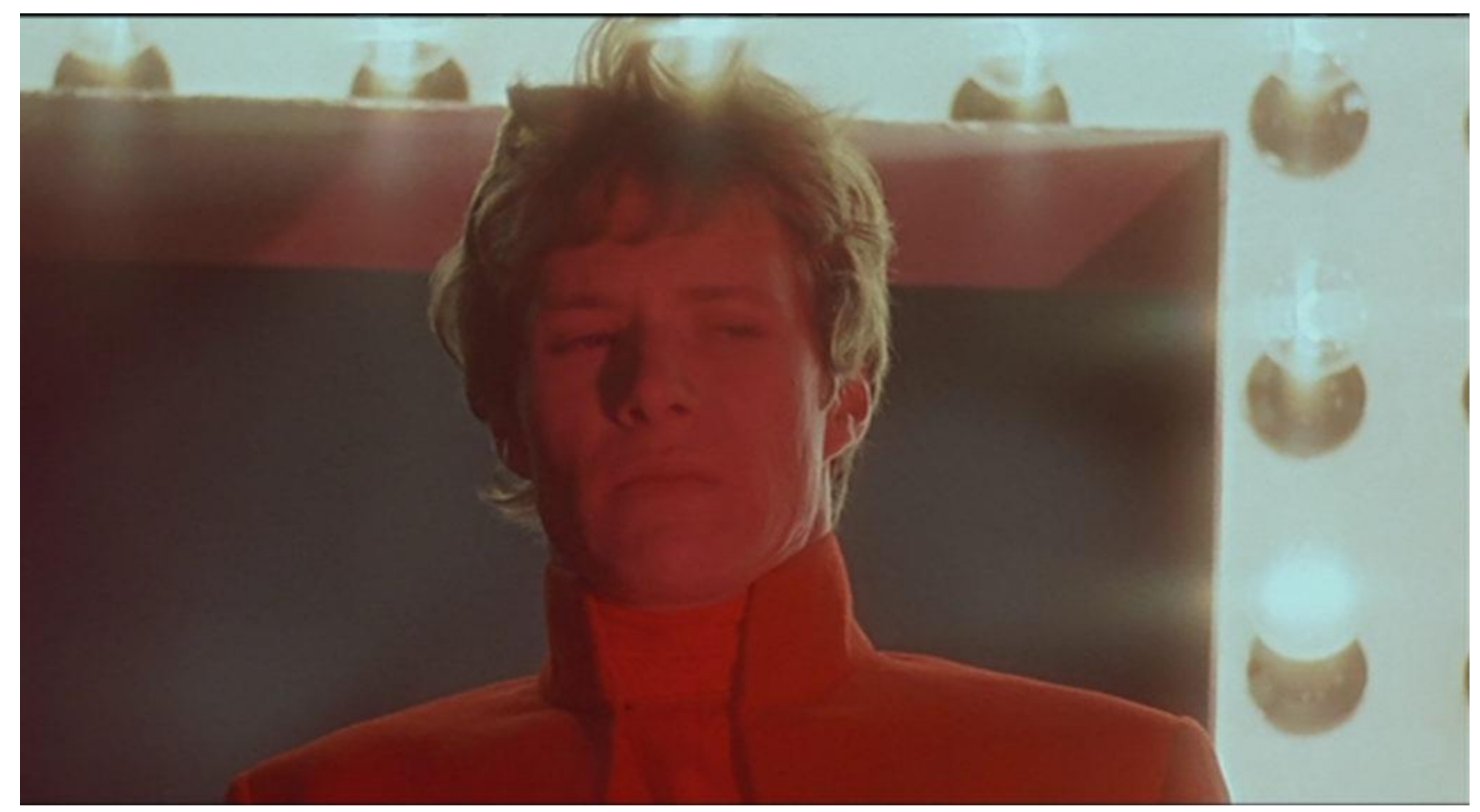

Figure 18: Still from Privilege (Peter Watkins, 1967)

The suffusion of the entire image with one colour recalls the use of the same effect using pink during Helen Mirren's performance in Herostratus. As argued above, the shots attempt to unify the image while signalling heightened emotional intensity as one colour dominates the frame in a way that is contrary to dominant conventions of photographic representation. The technique was used in other films to signal traumatic moments experienced by a character, such as when Sister Ruth loses consciousness in Black Narcissus (Powell and Pressburger, 1947), and as the trigger for Marnie's extreme emotional reactions in Marnie (Alfred Hitchcock, 1964). In Privilege and Herostratus it also indicates a loss of control as the characters 'fall into colour' in the sense that Batchelor identifies when describing colour as '[a] drug, a loss of consciousness, a kind of blindness - at least for a moment. Colour requires, or results in, or perhaps just is, a loss of focus, of identity, of self ${ }^{33}$ Such cases highlight the power of colour, how pure colour suffusion appears to ultimately consume the person with whom is it associated: they 'become' the colour but have lost control. This observation extends the foregoing commentary on how glossiness and saturation are powerful visual conventions embedded within advertising cultures: the 'total' colour image in this context represents an extreme visual expression of this tendency.

The red-suited Steven sings of being saved by religion, but it is only when he is watching himself later on television that he fully realises the depths of his manipulation. The colours worn by him throughout the film function as uniforms that are expressive of the branding with which he has become merged, rather than reflecting his individuality: he is 'Blue' then he is 'Red'. Although red is sometimes associated with religion, for example the red worn by Catholic cardinals, here the colour has been appropriated by the regime. It recalls Eisenstein's observations on colour and context:

What is unique in an image and what can blend essentially with it are absolute only in the conditions of a given context, of a given iconography, of a given construct... Red! The colour of the revolutionary flag. And the colour of the ears

of a liar caught red-handed. The colour of boiled crayfish - and the colour of a 'crimson' sunset. The colour of cranberry juice - and the colour of warm human blood. ${ }^{34}$ 
These ideas are important, since when considering colour's relationship to power structures the film illustrates how context influences meaning, and how 'propagandist' colours tend to negate differentiation, nuance or any potential for individual agency in their deployment. This negation of complexity can also be related to the glossy appearance of products which are staged to prevent the emergence of ambiguous or contradictory meanings. Following Steven's speech articulating his desire to be an individual ('you've made me nothing', he despairs), he is banned from television appearances and declared 'a social problem'. The concluding voice-over informs us that 'all that remained of Steven Shorter were a few old records and a piece of archive film with the sound, of course, removed'. The archive film we are shown is black and white; Steven's image has indeed been stripped of its emotive visual, aural and chromatic power.

In Herostratus a different approach is taken to colour, power and the main protagonist. Max wears white throughout the film, which is perhaps fitting for someone whose status within advertising has yet to be defined - the stunt is about staging his own death rather than perpetuating a 'brand'. When discussing Max's contract, the advertising executives tell him they want to construct a 'good, selling image' for him, and that his crusade must appear heroic, rather than motivated by the personal, negative and nihilistic ideas Max has indicated. Back in the studio, he watches a news item reporting the plan and grimaces when he hears his protest described as quasireligious and against 'clear signs of degeneracy in our behaviour and way of life', while speculating that the whole stunt could backfire if no one is interested whether Max lives or dies. Just as in Privilege, when Steven's cathartic moment is prompted by him viewing televisual reportage of himself, Max's response to his own manufactured image is a violent outburst, smashing up the television.

The next scene is a script rehearsal, and it again becomes clear that Max is being used to articulate a reactionary message about annihilating undesirable elements of society. The similarities with Privilege are clear: the same appropriation of an individual is taking place. The equation between advertising and sacrifice is made even more graphically in a subsequent disturbing sequence with a jazz soundtrack that intercuts a striptease with an animal being slaughtered at an abattoir. The colours are vivid and hyper-artificial in the montage that cuts between scenes from a psychedelic projection show that slashes gaudy colours across a woman's body, with the excess of blood and tearing of flesh seen in the slaughterhouse, and one shot of the bubbling residue filling the entire frame. 


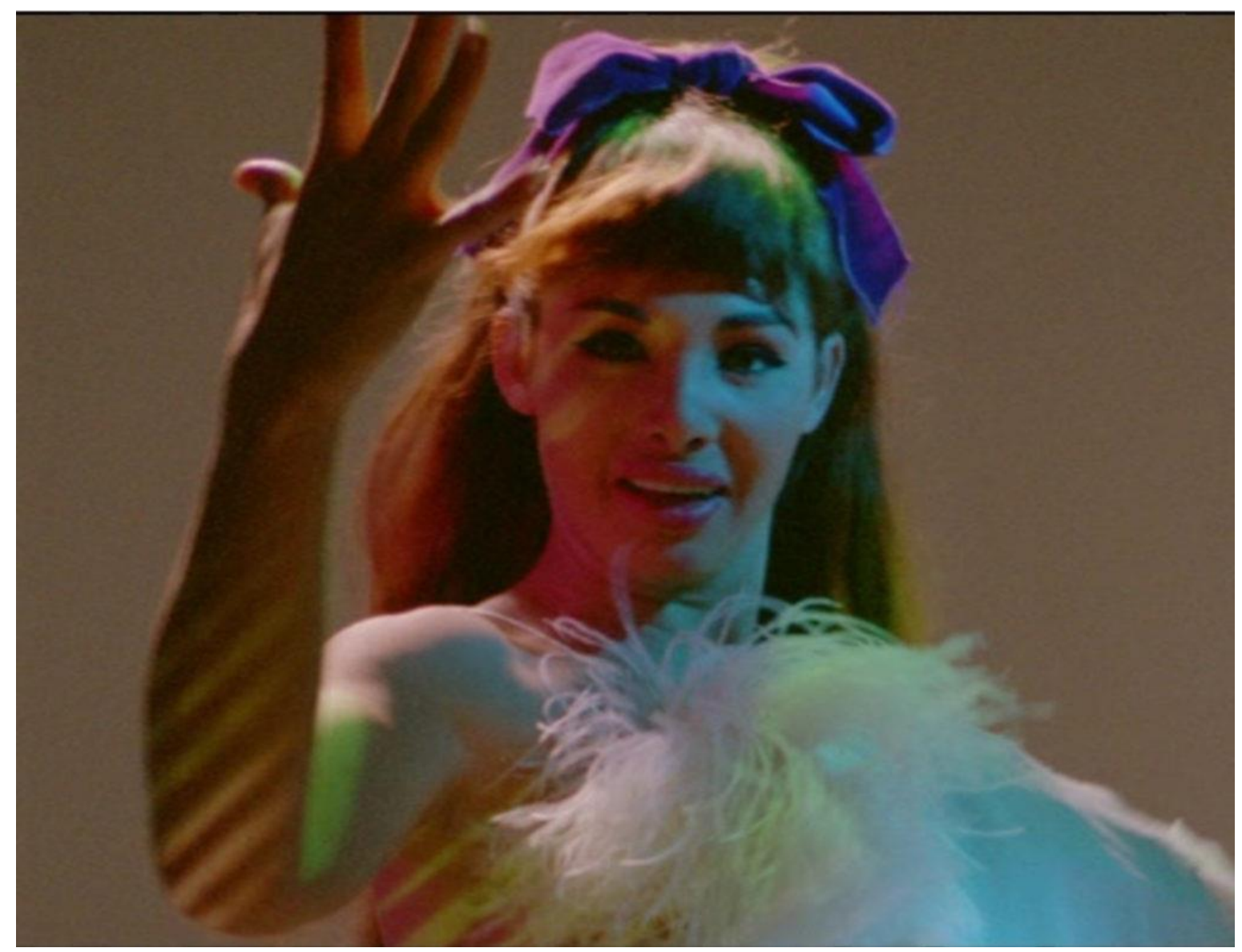

Figure 19: Still from Herostratus (Don Levy, 1967)

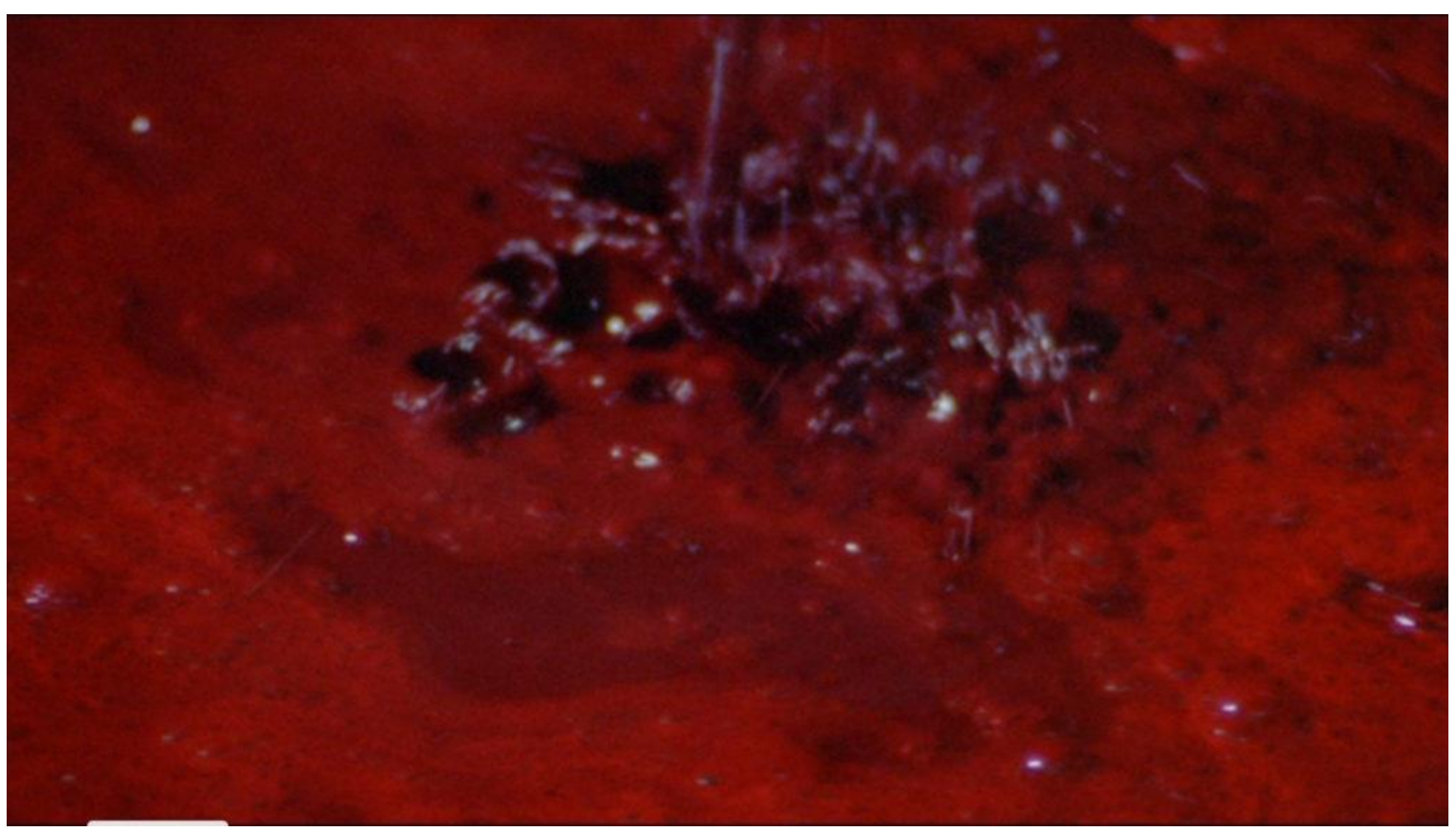

Figure 20: Still from Herostratus (Don Levy, 1967)

Similarities between the two contexts are suggested: flesh is exploited in both, and this idea recalls the earlier collaged image of a woman's head emerging from a piece of meat. This shocking imagery then links to a series of slow-shutter shots, one of which is intercut to match the pose of 
the woman we have seen in the previous sequence, that capture Max's writhing face with the same extreme distortion seen in paintings such as Francis Bacon's 'Self Portrait' (1969).

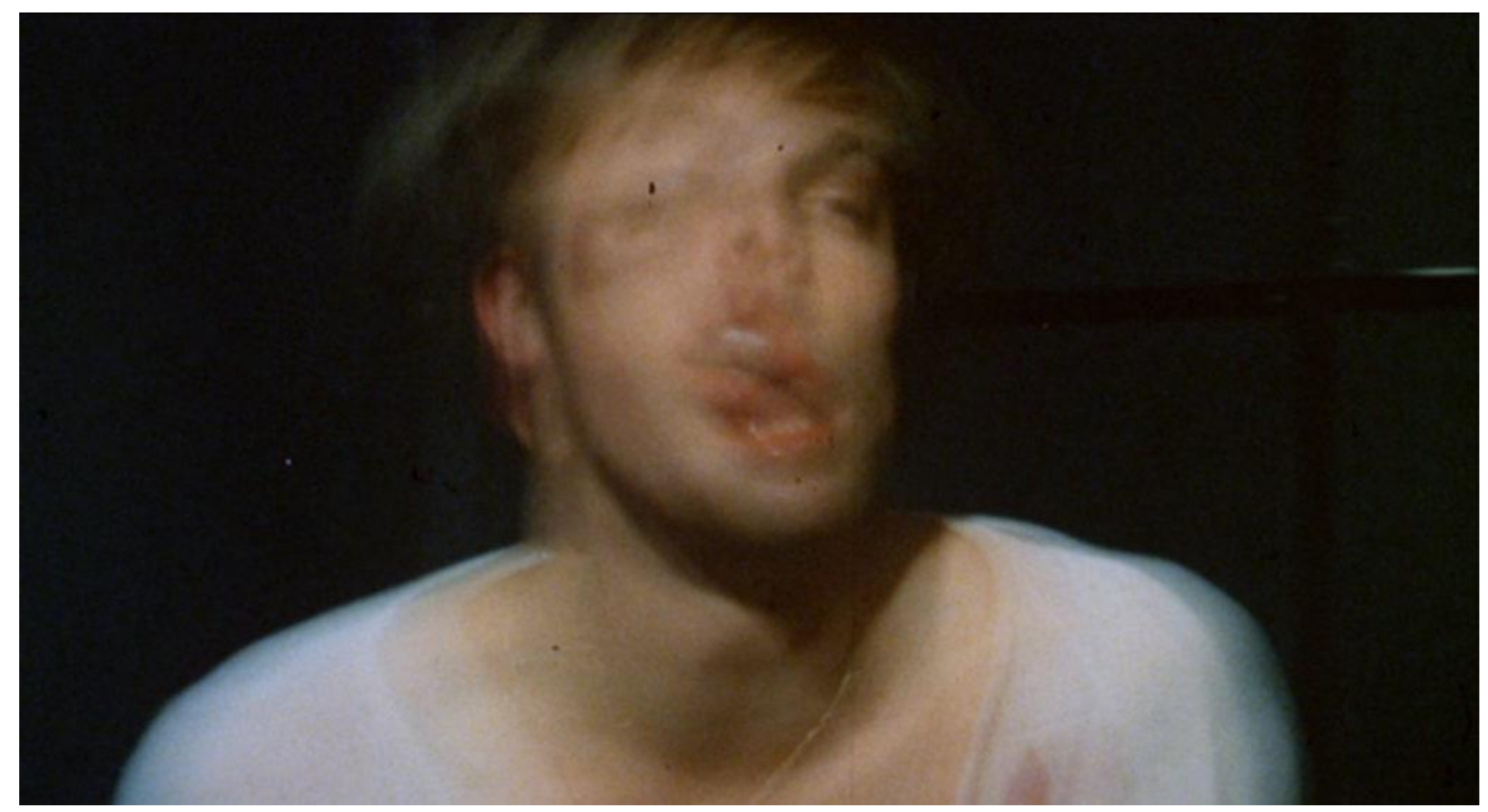

Figure 21: Still from Herostratus (Don Levy, 1967)

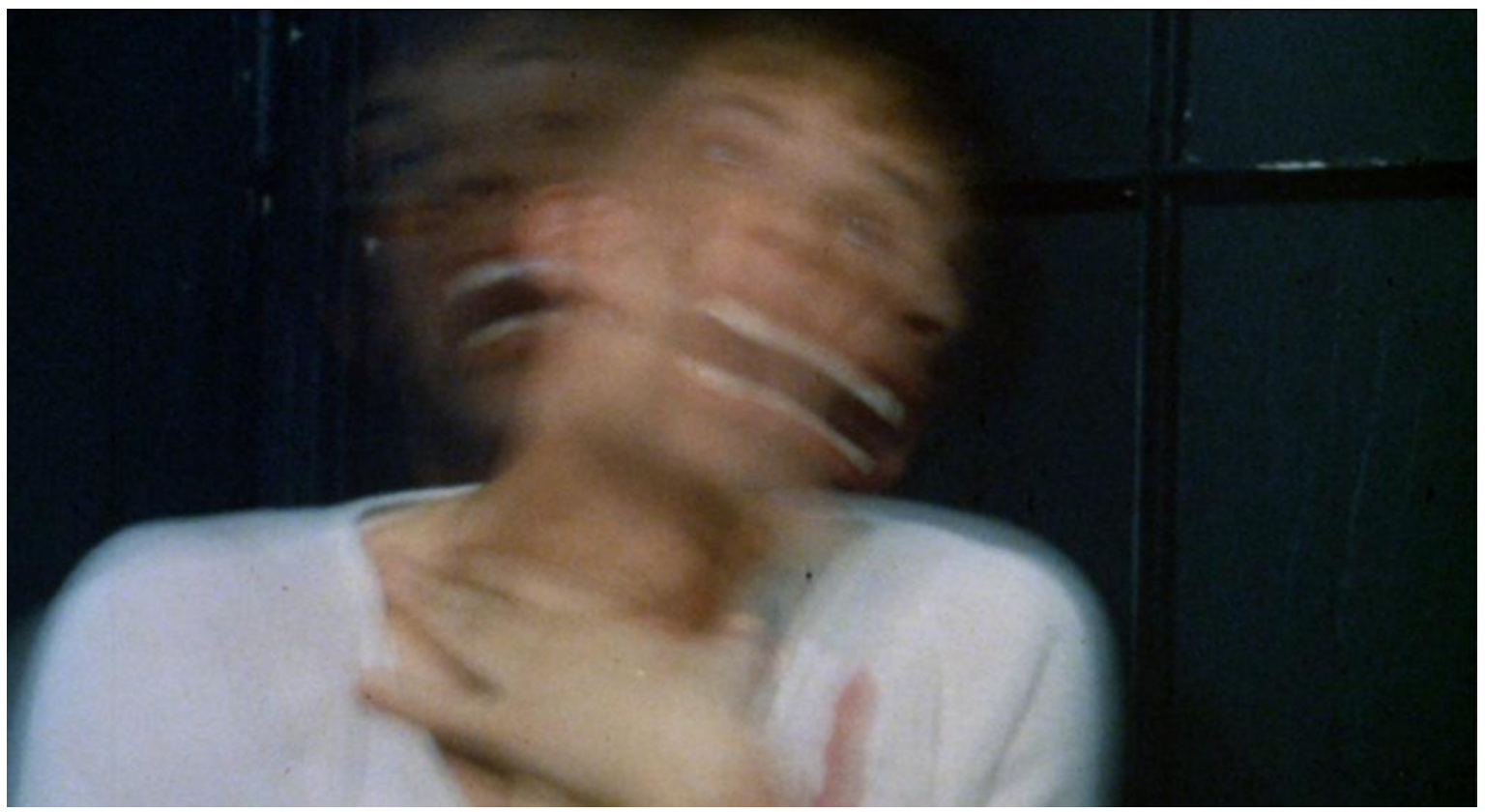

Figure 22: Still from Herostratus (Don Levy, 1967)

This apposite intertextual allusion indeed invites comparison with the 'disruption of constant colour' found in Bacon's work, 'his disruption of fields of perceived evenness and unity of tone' that Chare interprets as 'symptomatic of a release of aggressive impulses'. 35 This describes Max's dilemma as he comes to the painful realisation that he is no more than meat to the Farson Advertising company; his body is an expendable commodity to be treated as any other product. Levy intended these shots to 'strike the right chord emotionally at a particular time' which might be 'indecision, or self-doubt, or revulsion'. ${ }^{36}$ They are interspersed with frenetic, single-frame 
blocks of orange and red; shots of Max running in the open air; close-ups of Farson; somberlooking commuters on the London tube, and very brief glimpses of concentration-camp victims extracted from archival footage. These create an impression of Max's disturbed thoughts and his struggle, expressed through his moving body and contorted face, for freedom from the oppressive socio-political-historical forces represented by these images. Levy likened this collage-like approach of repeating shots to harmony and counterpoint in music in which 'shots return in a different context but still have the meanings they had before'. ${ }^{37}$ As it gathers momentum, the multi-layered sequence of images becomes excessively resonant and expressive.

This technique is also used shortly afterwards for Farson's assistant Clio whose relationship to Max is ambiguous. She appears in the studio wearing an orange and pink-tinged, hooded cape made of synthetic, sparkly material with a metallic sheen. Intercut with images of the striptease woman, this attire, seen in long-shots and close-ups as she twirls to demonstrate its glistening contours, is both mysterious and unsettling in its resemblance to the colours used for the 'commercial' featuring Helen Mirren. As she turns, she is transformed by slow-shutter effects that contort her face in a series of still shots of swirling, blurred movements as her image is made increasingly strange, almost disfigured.

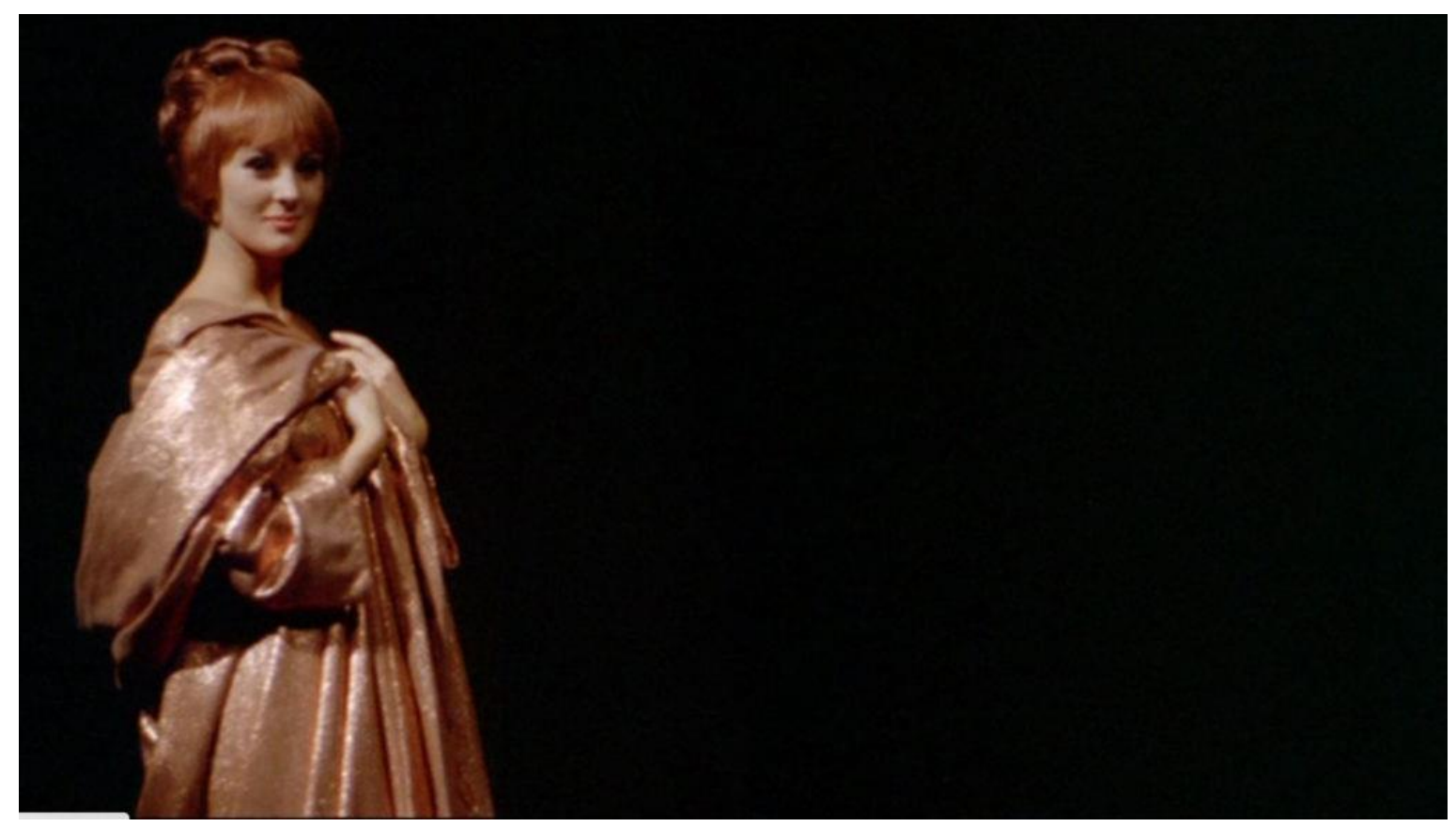

Figure 23: Still from Herostratus (Don Levy, 1967) 


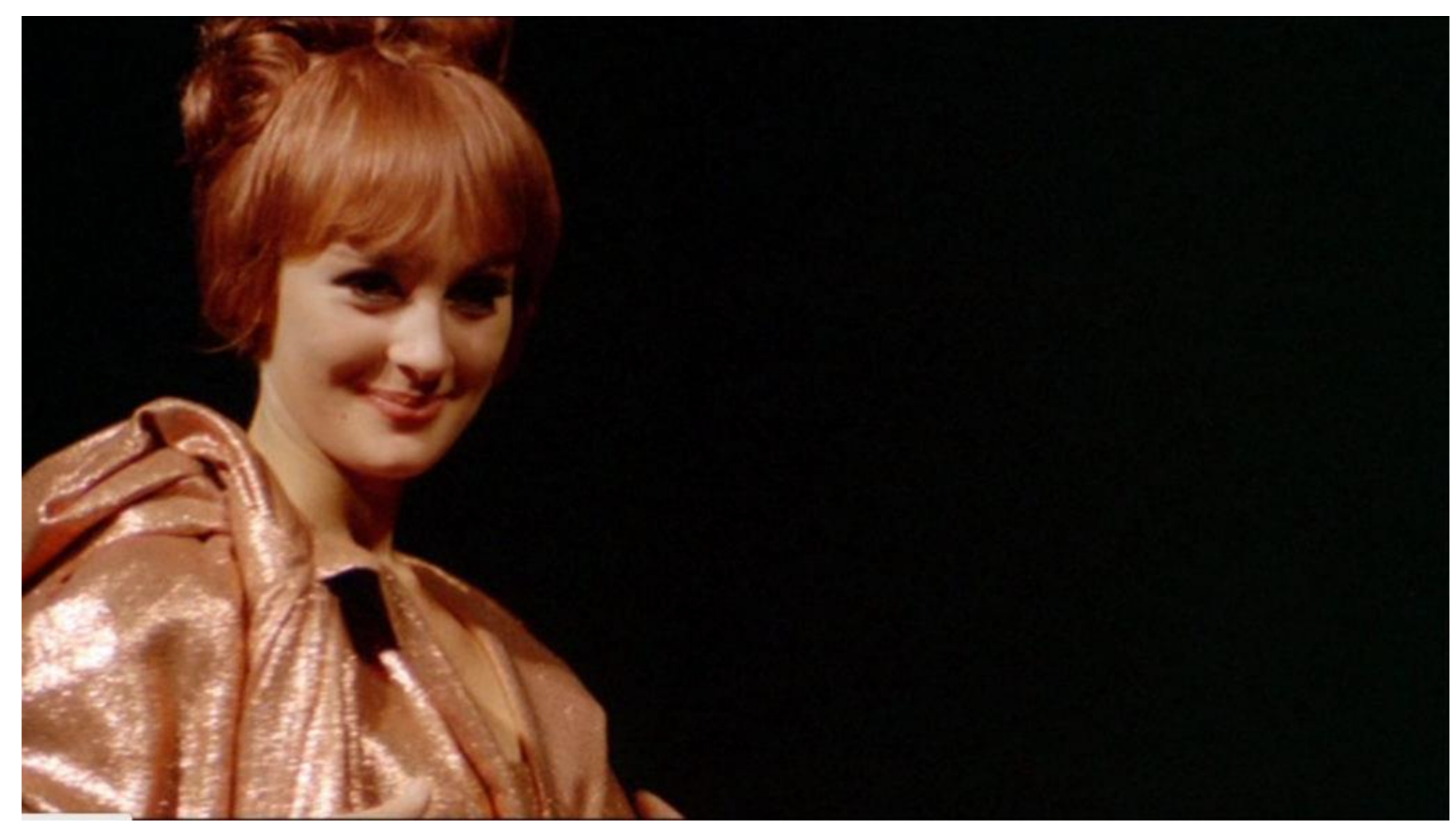

Figure 24: Still from Herostratus (Don Levy, 1967)

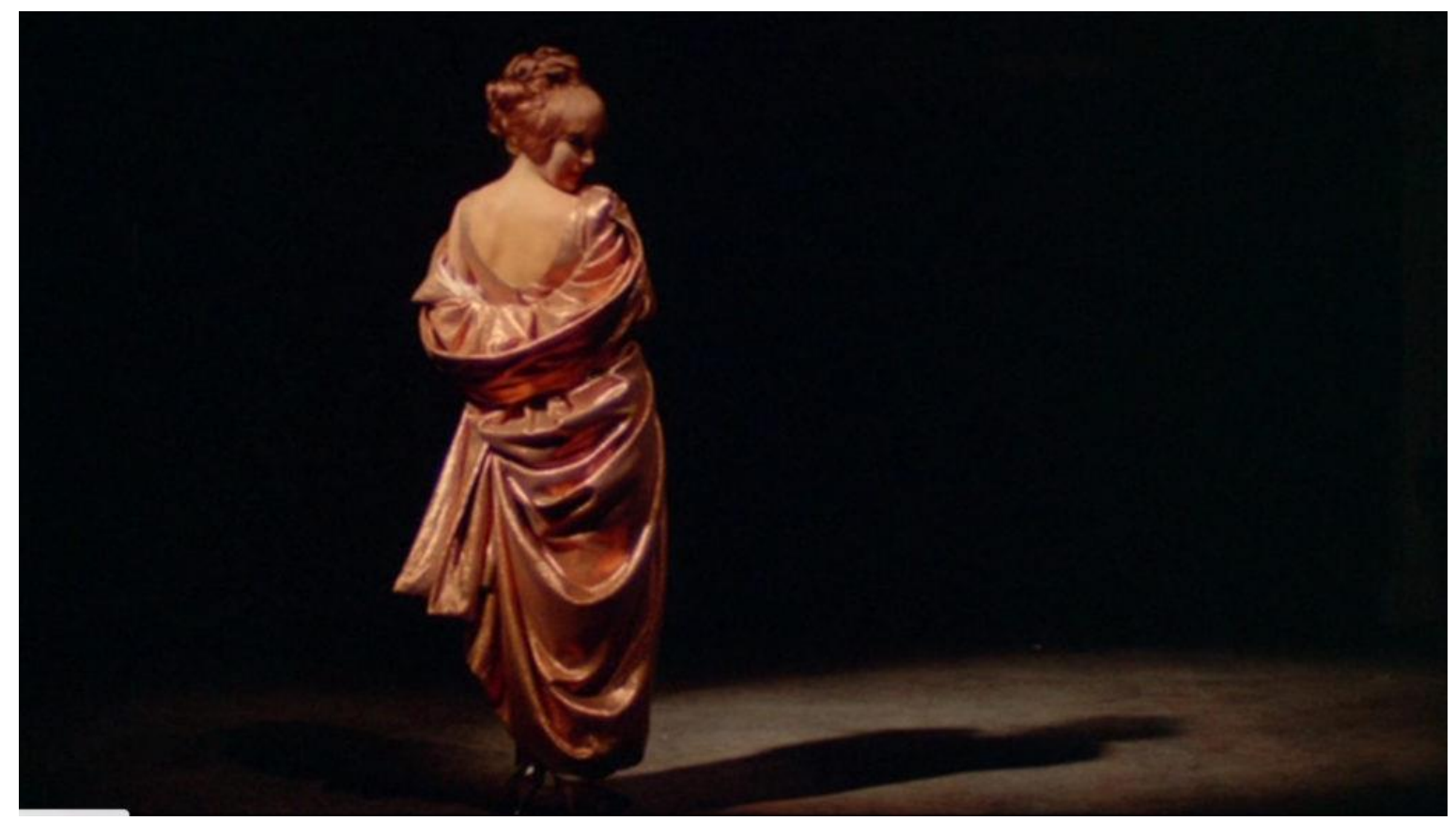

Figure 25: Still from Herostratus (Don Levy, 1967) 


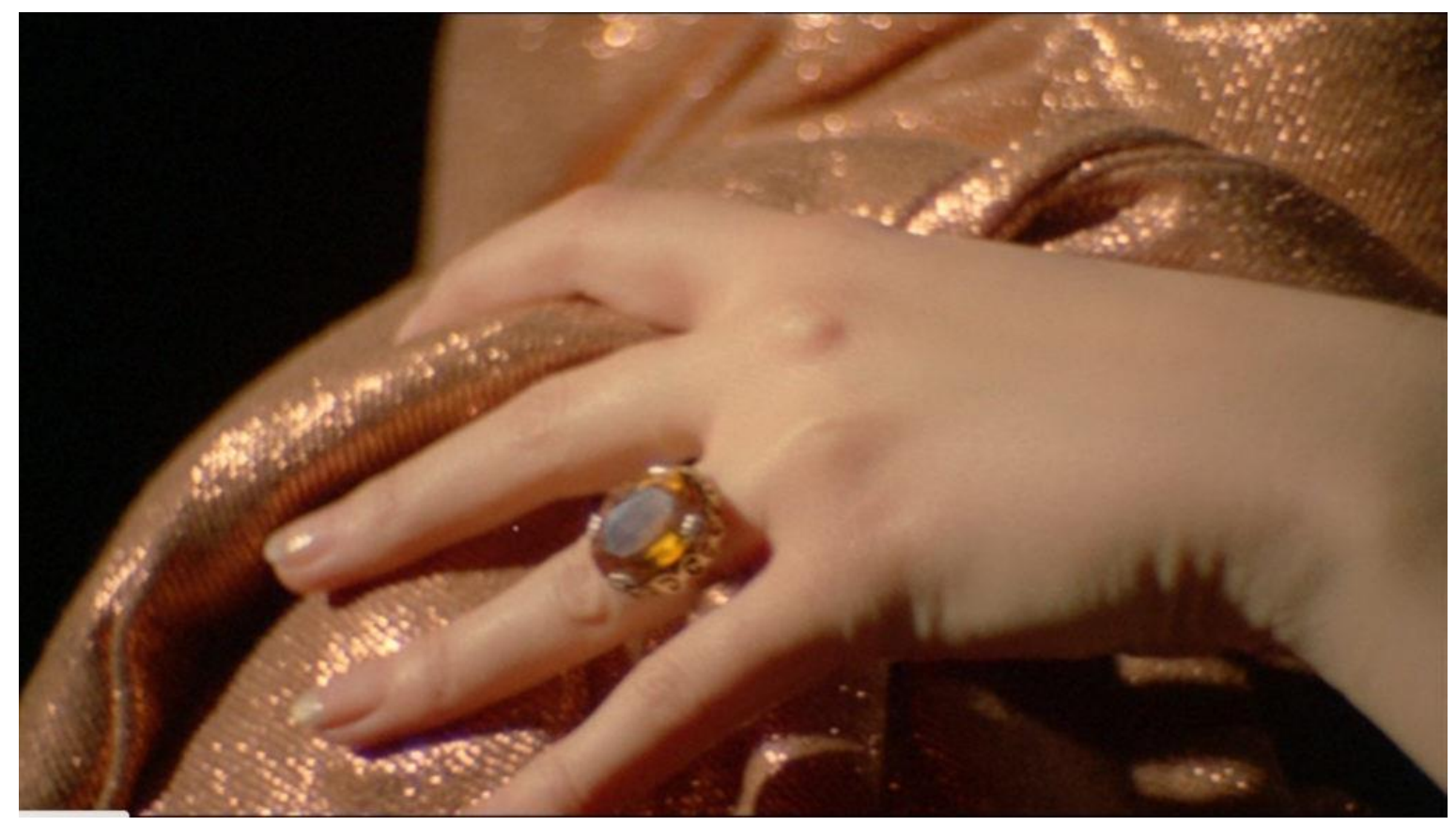

Figure 26: Still from Herostratus (Don Levy, 1967)

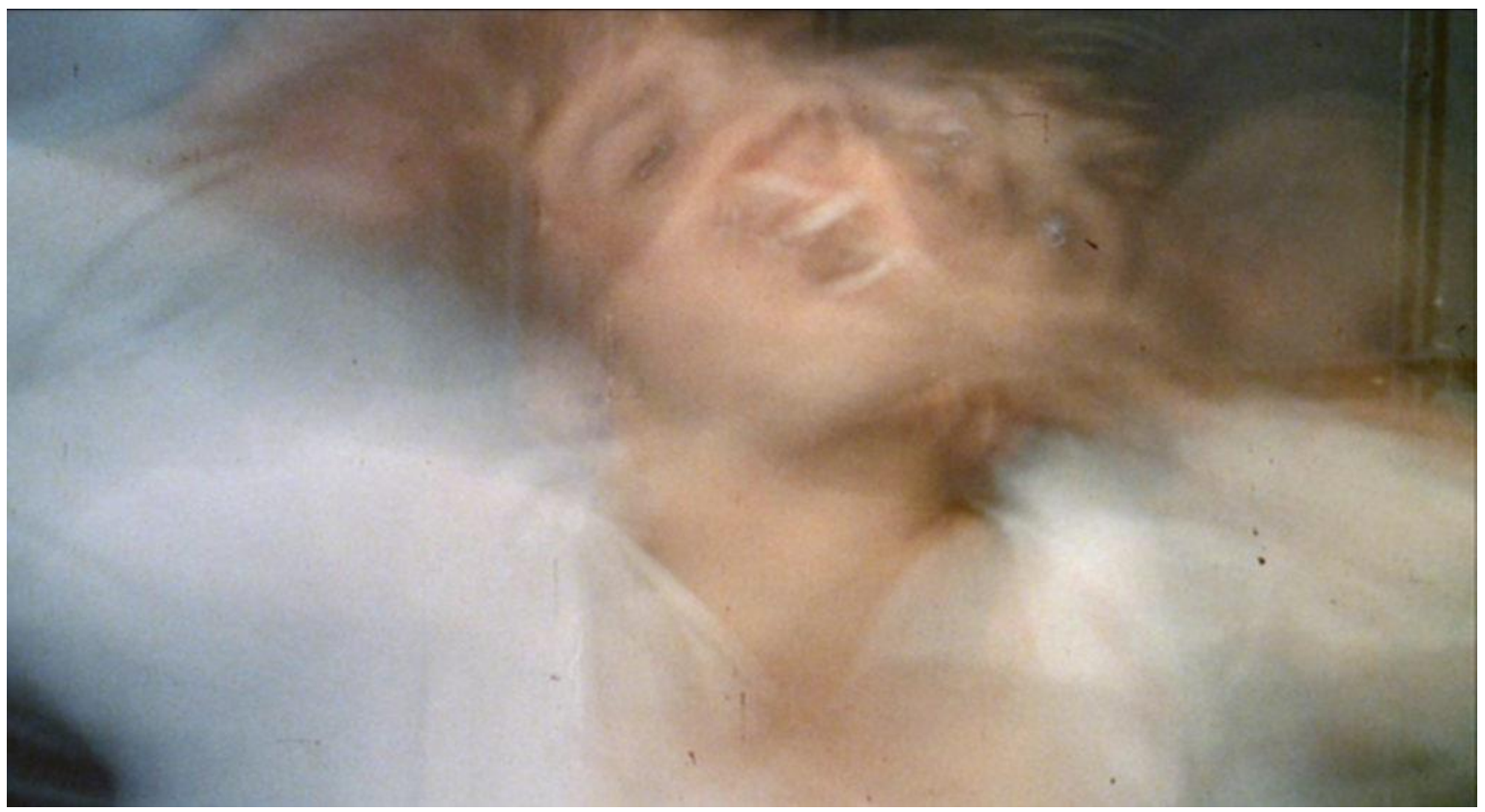

Figure 27: Still from Herostratus (Don Levy, 1967)

These link her visually to the Francis Bacon-like shots of Max, perhaps suggesting they both seek a 'release of aggressive impulses' through 'revulsion' as the camera captures something of both subjects' painful interiority. These disparate images, momentarily flashed on the screen and almost ghostly in appearance, can also be likened to the 'subliminal' advertising effects disapproved of by critics of the political and ethical implications of the technique. The succession of alienating shots contributes to the film's 'intellectual structures' in a non-verbal style that Levy used to reinforce his own oppositional political stance. ${ }^{38}$ Similar to Steven's smashing of the television in Privilege, they represent brief moments of revulsion expressed by the characters as they gain painful insight into their predicaments. 
The fractured style of Herostratus disrupts the illusion of seamlessness associated with advertising but achieves this by using more overtly experimental techniques than seen in Privilege. Levy described his approach as consisting of 'emotional rhythms' in a 'network of resonances' between shots, sounds, interspersed found footage and colour. ${ }^{39}$ He used highly controlled, mixed colour temperatures to accentuate the hues in every frame. He considered the emotional effect of colour to be very important, deliberately under-exposing some scenes to deepen the saturation of colours. Shots of locations were often repeated but each time showing a different weather situation. This approach was designed to provide 'reverberation for the psychological content of a scene'. ${ }^{40}$ The love scene between Clio and Max towards the end of the film, for example, has subtle colour changes from warm yellows to cool blues, reflecting the change of mood as the scene develops.

Vivid, contrasting colours feature in montage-like shots that are interspersed, apparently at random, of women in seductive poses: one in black leather with bright red lips, and in the scenes already referenced featuring Helen Mirren as a pink-clad dancer and the woman lit by coloured light-show effects. In terms of gender politics women are identified with the superficial, exploitative culture that frustrates Max. There is a tension within the film between the spectacle of this imagery which demonstrates the 'to-be-looked-at-ness' of erotic, visual presentation of women identified by Mulvey, and its generation of insightful, satirical parodies concerning the sexualization of women, particularly conveyed through Mirren's masquerading performance. ${ }^{41}$ In this way, the film constitutes a barrage of visual imagery as colours, shot juxtapositions and collage techniques accumulate to produce a disturbing take on contemporary society. Rancière identified this technique in 'progressive fictions' such as Godard's La Chinoise (1967) that similarly deployed 'a mixture of beautiful images and painful speeches, of fictional affects and realist references, that when combined compose a symphony on which Marxism imposes itself as the theme or melody necessarily being sought by the mass orchestration'. ${ }^{42}$ The 'organic unity', in Eisenstein's sense of an integrated work of art, to be found in Herostratus is its orchestration of distancing effects, including the deployment of colours which like montage, postulate variable meanings which are dependent on context. ${ }^{43}$ These conspire to produce a devastating commentary on contemporary society, a radical critique without suggesting a clear way forward.

This article has shown how filmmakers operating outside of mainstream, genre cinema can offer complex observations about the theme of advertising, and critique how colour can be used for persuasive and political ends. A number of strategies have been highlighted in Privilege and Herostratus that present and expose the recurrent, stylistic conventions which drive commercial exploitation. While Watkins and Levy took different approaches, both films featured devastating critiques of the glossiness associated with advertising culture's surface values and saturated colours. By locating often disturbing images within editing structures and performances designed to provoke active contemplation, colours are at the centre of recurrent processes of recontextualisation. In 1967, the cultural moment was right for such radical interventions. For Watkins in particular, it represented an assertive 'demonstration phase' of experimentation with a bold colour design, whereas in subsequent films, particularly Edvard Munch (1972) he aimed to 'control' colour towards a 'muted and extremely pastel' look..$^{44}$ Levy used colour as an integral element of his work, enhancing the impact of montage, hybridity and performance. Both directors shared a profound distrust of contemporary commercial advertising campaigns and the people who ran them, basing their films on the exploitation of the younger generation rather than Walker's 
more positive interpretation of a youth-based 'corporate identity' helping to erode social distinctions. ${ }^{45}$ In doing so, they suggest that when used creatively colour, lighting and costume can be mobilised to provoke new, critical understandings and interpretations of cultural phenomena that might otherwise appear inviolable. Even though both Steven and Max ultimately fail in their challenges to the forces that used and controlled them, Privilege and Herostratus suggest how striking aesthetic approaches, including colour, are key to oppositional filmmaking practices.

${ }^{1}$ Eric P. Danger, Using Colour to Sell (London: Gower Press, 1968), 48.

2 Alexander Walker, Hollywood, England: The British Film Industry in the Sixties (London: Michael Joseph, 1974), 131.

3 James Curtis, "The Creative Revolution, 1962-72", Campaign, 20 June 2002. Accessed 18 March 2020.

https://www.campaignlive.co.uk/article/creative-revolution-1962-1972-social-climate-swinging-sixties-fashionvouth-fore-brands-embraced-tv-advertising-used-innovatively-forge-distinctive/148593

${ }^{4}$ Charles Marowitz, Campaign, 11 Sept 1970, 23.

${ }^{5}$ Schwarzkopf, "They do it with Mirrors", 135-6.

${ }^{6}$ Vance Packard, The Hidden Persuaders (New York: Doubleday, 1957).

7 In 2016, the British Film Institute restored Privilege and released it on DVD/Blu-ray (BFIB1107). In 2011, the British Film Institute restored Herostratus and released it on DVD/Blu-ray (BFIB1104). The analyses in this article are based on these versions.

${ }^{8}$ Fredric Jameson, Signatures of the Visible (London: Routledge, 1992): 191-2; Eirik Hanssen, "Eisenstein in Colour" Konsthistorisk Tidskrift, vol. 74, no. 4 (2004): 220; David Batchelor, Chromophobia (London: Reaktion Books, 2000$): 51$.

${ }^{9}$ Robert Leach, "Eisenstein's Theatre Work" in Ian Christie and Richard Taylor (eds), Eisenstein Rediscovered (London and New York: Routledge, 1993), 112.

${ }^{10}$ Peter Watkins in Lester Friedman, "The Necessity of Confrontation Cinema - Peter Watkins interviewed”,

Literature/Film Quarterly, vol. 11, no. 4 (1983): 237.

${ }^{11}$ Watkins in Friedman, "The Necessity of Confrontation Cinema”, 240.

12 Robert Murphy, "Privilege", in booklet accompanying DVD/Blu-ray of Privilege (BFIB1107), 2.

13 Don Levy, interview 1973 included on DVD/Blu-Ray of Herostratus (BFIB1104).

${ }^{14}$ Jeroen J.M. Grunzier, Romain Vergne and Karl R. Gregenfurtner, "The effects of surface gloss and roughness on color constancy for real 3-D objects”, Journal of Vision, vol. 14, no. 16 (Feb 2014): 1-20.

15 Jameson, Signatures of the Visible, 191-92.

16 Jameson, Signatures of the Visible, 193.

17 Watkins in Friedman, "The Necessity of Confrontation", 238.

18 Don Levy interviewed in Cinema, 2 (March 1969): 14.

${ }^{19}$ Charles R. Warner, "Shocking Histoire(s): Godard, Surrealism, and Historical Montage”, Quarterly Review of Film and Video, vol. 25, no. 1 (2007): 1-15.

${ }^{20}$ Roberta Sassatelli, "Interview with Laura Mulvey", Theory, Culture and Society, vol. 28, no. 5 (2011): 132.

${ }^{21}$ Judith Williamson, Decoding Advertising (London: Marion Boyars, 1978) and Sarah Niblock, "Advertising" in Fiona Carson and Claire Pajaczkowska (eds), Feminist Visual Culture (Edinburgh: Edinburgh University Press, 2000).

${ }^{22}$ Leslie Corina, "Motivation Research", Socialist Commentary, July 1960, $23 \mathrm{f}$.

${ }^{23}$ Judith Butler, Gender Trouble: Feminism and the Subversion of Identity (London: Routledge, 1990).

${ }^{24}$ Danger (Using Colour to Sell, 50) noted that, in 1968, orange was a 'trend colour'.

${ }^{25}$ David Batchelor, The Luminous and the Grey, (London: Reaktion Books, 2014), 52.

${ }^{26}$ Dominique Grisard, “Real Men Wear Pink?” A Gender History of Color' in Bright Modernity: Color, Commerce, and Consumer Culture, eds. Regina Lee Blaszczyk and Uwe Spiekermann (Cham, Switzerland: Palgrave Macmillan, 2017), 87.

${ }^{27}$ Regina Lee Blaszczyk, "The Color Schemers: American Color Practice in Britain, 1920s-1960s" in Bright Modernity: Color, Commerce, and Consumer Culture, eds. Regina Lee Blaszczyk and Uwe Spiekermann (Cham, Switzerland: Palgrave Macmillan, 2017), 191-225.

${ }^{28}$ Michel Pastoureau, Blue (Princeton, New Jersey: Princeton University Press, 2001), 180.

${ }^{29}$ Watkins in Friedman, "The Necessity of Confrontation", 238. 'Counter-revolutionary' is perhaps a strange phrase to use in this context, since the sentiment of Watkins' statement is closer to 'counter-cultural'.

${ }^{30}$ Jonathan Faiers, "Yellow is the new red, or clothing the recession and how the shade of shame became chic", in Colors in Fashion, eds. Jonathan Faiers and Mary Westerman Bulgarella (London: Bloomsbury, 2017), 96.

31 Watkins in Friedman, "The Necessity of Confrontation", 240.

${ }^{32}$ Watkins in Friedman, "The Necessity of Confrontation", 243.

${ }_{33}$ David Batchelor, Chromophobia (London: Reaktion Books, 2000), 51. 
34 Sergei Eisenstein, "On Colour", reprinted in Color: The Film Reader, eds. Angela Dalle Vacche and Brian Price (London; Routledge, 2006), 107.

35 Nicholas Chare, "Hues and cries: Francis Bacon's use of colour", in New Directions in Colour Studies, eds. Carole P. Biggam, Carole A. Hough, Christian J. Kay and David R. Simmons (Amsterdam: John Benjamins Publishing, 2011), 179.

${ }^{36}$ Don Levy quoted in David Curtis, A History of Artists' Film and Video in Britain (London: British Film Institute, 2007), 175; and Don Levy interviewed by Bruce Beresford in Cinema, 2 (March 1969): 15.

${ }^{37}$ Don Levy interviewed in Cinema, 2 (March 1969): 15.

${ }^{38}$ Don Levy, audio interview 1973, included on Herostratus DVD/Blu-ray (BFIB1104).

${ }^{39}$ Levy interview 1973, BFIB1104.

${ }^{40}$ Levy interview 1973, BFIB1104.

${ }^{41}$ Laura Mulvey, "Visual Pleasure and Narrative Cinema", Screen, vol. 16, no. 3: 11. Italics as in original quotation.

42 Jacques Rancière, "The Red of La Chinoise", originally published in Trafic, no. 18 (Spring 1996). Accessed 29

March 2020. https://www.diagonalthoughts.com/?p=1610

43 Hanssen, "Eisenstein in Colour", 218.

${ }^{44}$ Watkins in Friedman, “The Necessity of Confrontation”, 242.

45 Walker, Hollywood, England, 131.

\section{Bibliography}

Batchelor, David. Chromophobia. London: Reaktion Books, 2000.

Batchelor, David. The Luminous and the Grey. London: Reaktion Books, 2014.

Butler, Judith. Gender Trouble: Feminism and the Subversion of Identity. London: Routledge, 1990.

Chare, Nicholas. "Hues and cries: Francis Bacon's use of colour". In New Directions in Colour Studies, edited by Carole P. Biggam, Carole A. Hough, Christian J. Kay and David R. Simmons, 171-180. Amsterdam: John Benjamins Publishing, 2011.

Corina, Leslie. "Motivation Research". Socialist Commentary, July 1960, $23 \mathrm{f}$.

Curtis, David. A History of Artists' Film and Video in Britain. London: British Film Institute, 2007. Curtis, James. “The Creative Revolution, 1962-72”. Campaign, 20 June 2002. Accessed 18 March 2020. https://www.campaignlive.co.uk/article/creative-revolution-1962-1972-social-climateswinging-sixties-fashion-youth-fore-brands-embraced-tv-advertising-used-innovatively-forgedistinctive/148593

Danger, Eric P. Using Colour to Sell. London: Gower Press, 1968.

Dentith, Simon. Parody. London: Routledge, 2000.

Eisenstein, Sergei. “On Colour”. Reprinted in Color: The Film Reader, edited by Angela Dalle Vacche and Brian Price, 105-117. London; Routledge, 2006,

Faiers, Jonathan. "Yellow is the new red, or clothing the recession and how the shade of shame became chic". In Colors in Fashion, edited by Jonathan Faiers and Mary Westerman Bulgarella, 95116. London: Bloomsbury, 2017.

Friedman, Lester. "The Necessity of Confrontation Cinema - Peter Watkins interviewed". Literature/Film Quarterly, vol. 11, no. 4 (1983): 237-248.

Grisard, Dominique. “"Real Men Wear Pink?’ A Gender History of Color”. In Bright Modernity: Color, Commerce, and Consumer Culture, edited by Regina Lee Blaszczyk and Uwe Spiekermann, 7796. Cham, Switzerland: Palgrave Macmillan, 2017.

Grunzier, Jeroen J.M., Romain Vergne and Karl R. Gregenfurtner. "The effects of surface gloss and roughness on color constancy for real 3-D objects". Journal of Vision, vol. 14, no. 16 (Feb 2014): $1-20$.

Hanssen, Eirik. "Eisenstein in Colour”. Konsthistorisk Tidskrift, vol. 74, no. 4 (2004): 212-227. 
Jameson, Fredric. Signatures of the Visible. London: Routledge, 1992.

Leach, Robert. "Eisenstein's Theatre Work". In Eisenstein Rediscovered edited by Ian Christie and Richard Taylor. London and New York: Routledge, 1993.

Levy, Don. Interviewed by Bruce Beresford. Cinema, 2 (March 1969): 14-17.

Marowitz, Charles. Campaign, 11 Sept 1970, 23.

Mulvey, Laura. "Visual Pleasure and Narrative Cinema". Screen, vol. 16, no. 3 (1975): 6-18.

Murphy, Robert. "Privilege". In booklet accompanying DVD/Blu-ray of Privilege (BFIB1107), 2.

Niblock, Sarah. "Advertising". In Feminist Visual Culture edited by Fiona Carson and Claire Pajaczkowska. Edinburgh: Edinburgh University Press, 2000.

Packard, Vance. The Hidden Persuaders. New York: Doubleday, 1957.

Pastoureau, Michel. Blue. Princeton, New Jersey: Princeton University Press, 2001.

Rancière, Jacques. "The Red of La Chinoise". Originally published in Trafic, no. 18 (Spring 1996). Accessed 29 March 2020. https://www.diagonalthoughts.com/?p=1610

Sassatelli, Roberta, "Interview with Laura Mulvey", Theory, Culture and Society, vol. 28, no. 5 (2011): $123-43$.

Schwarzkopf, Stefan. "They do it with Mirrors: Advertising and British Cold War Consumer Politics". Contemporary British History, vol. 19, no. 2 (2007): 133-150.

Walker, Alexander. Hollywood, England: The British Film Industry in the Sixties. London: Michael Joseph, 1974.

Walter, W. Grey. The Living Brain. New York: W.W. Norton and Co., 1953.

Warner, Charles R. "Shocking Histoire(s): Godard, Surrealism, and Historical Montage". Quarterly Review of Film and Video, vol. 25, no. 1 (2007): 1-15.

Williamson, Judith. Decoding Advertising. London: Marion Boyars, 1978.

\section{Filmography}

Black Narcissus. Michael Powell and Emeric Pressburger, UK, 1947.

Edvard Munch. Peter Watkins, UK, 1972.

Herostratus. Don Levy, UK, 1967.

La Chinoise. Jean-Luc Godard, France, 1967.

Lonely Boy. Roman Kroitor and Wolf Koenig, Canada, 1962.

Marnie. Alfred Hitchcock, USA, 1964.

Privilege. Peter Watkins, UK, 1967.

Un chien andalou. Luis Buñuel, France, 1929.

The War Game. Peter Watkins, UK, 1965.

\section{About the Author}

Sarah Street is Professor of Film at the University of Bristol. Her publications include Colour Films in Britain: The Negotiation of Innovation, 1900-55 (2012), winner of the British Association of Film, Television and Screen Studies' Best Monograph Award, Color and the Moving Image: History, Theory, Aesthetics, Archive (co-edited with Simon Brown and Liz Watkins, 2013), and Deborah Kerr (2018). Her most recent book, Chromatic Modernity: Color, Cinema, and Media of the 1920s (2019, coauthored with Joshua Yumibe) was awarded the Katherine Singer Kovacs Book Award by the Society for Cinema and Media Studies. She has co-edited with Anders Steinvall the 'Modern Age' volume in Bloomsbury's Cultural History of Color series, to be published in 2021. 